\title{
Reestructuración del espacio continental en el contexto global: corredores multimodales en Norte y Centroamérica
}

\author{
Carlos Martner-Peyrelongue*
}

\begin{abstract}
This article provides some analytical elements to determine the potential and impact of some of the main projects for multi-modal and inter-oceanic corridors in North and Central America. This is done under the structural-systemic viewpoint of the Network and Flux Space, which emphasises the geo-economical and geo-political characteristics of a global space of networks and fluxes. Such a space is configured by extensive productive chains, which are increasingly globalised and integrated through new forms of international transport.
\end{abstract}

Keywords: multi-modal corridors, transport, territory, networks, fluxes, seaports.

\section{Resumen}

El presente artículo aporta elementos de análisis para determinar la potencialidad e impacto de los principales proyectos de corredores multimodales e interoceánicos de Norte y Centroamérica, bajo el enfoque estructural-sistémico del espacio de redes y flujos que enfatiza las determinaciones geoeconómicas y geopolíticas de un espacio global de redes y flujos, lo cual es configurado por extensas cadenas productivas crecientemente globalizadas e integradas a través de las nuevas formas de transportación internacional.

Palabras clave: corredores multimodales, transporte, territorio, redes, flujos, puertos.

*Instituto Mexicano del Transporte, México. Correo-e: cmartner@yahoo.com.mx, Carlos.Martner@imt.mx 


\section{Introducción}

En los albores del siglo xxi, la proliferación de propuestas y proyectos para construir corredores multimodales de transporte internacional vinculados al desarrollo de puertos concentradores y distribuidores de carga en contenedores (llamados puertos hubs o pivotes, en la literatura especializada), es particularmente intensa en el continente americano. En Sudamérica se habla insistentemente de desarrollar corredores bioceánicos atados a la creación de puertos pivotes en ambos litorales. En Centroamérica proliferan ideas y proyectos para implantar los llamados canales secos, que unirían el litoral del Pacífico con el del Atlántico, a través de nuevos puertos capaces de atender a grandes buques.

En México, se revive periódicamente el sempiterno proyecto del corredor de transporte del Istmo de Tehuantepec. En las últimas versiones, se ha planteado la reconversión de Salina Cruz (Pacífico) y Coatzacoalcos (Golfo de México) en puertos hubs vinculados al corredor multimodal que uniría ambos puertos con la red de transporte internacional.

Más novedoso es el llamado "Sistema de Seguridad Multimodal Transpacífico", presentado como el "Proyecto Bandera" de México en la Reunión APEC 2002, realizada en Los Cabos, Baja California. Este proyecto pretende enlazar principalmente flujos de contenedores entre el sudeste asiático (concentrados en Singapur) y el centro de los Estados Unidos (Missouri, Tennesse, Illinois, Texas, etc.) a través de los puertos mexicanos de Manzanillo o Lázaro Cárdenas y la frontera norte. Se trataría de una vía complementaria de los llamados land bridges o puentes terrestres estadounidenses, articulados desde los puertos de Long Beach y Los Ángeles, en California.

En el año 2004, el tema había cobrado tal relevancia en México que el gobierno federal junto con las principales agrupaciones y cámaras empresariales, las empresas ferroviarias, las navieras y los agentes aduanales, entre otros, suscribieron, ante el Presidente de la República, el llamado Acuerdo de Concertación para el Desarrollo de los Corredores Multimodales, cuya finalidad es definir, diseñar e implementar tales corredores en el territorio nacional, así como coordinar la actuación de los distintos actores para alcanzar alta eficiencia y menores costos en el traslado de las mercancías por estos ejes de transporte.

Por su parte, en Estados Unidos, ante la intensificación de los flujos de mercancías procedentes de Asia (sobre todo, de China), se plantean proyectos de ampliación de puertos y de corre- 
dores multimodales de trenes de doble estiba de contenedores, llamados puentes terrestres, (land bridges), porque son capaces de articular la Costa Oeste con la Costa Este de tal país, a partir de los puertos de ambos litorales.

Sin duda, la paulatina implementación de estos proyectos implicaría una reestructuración territorial de grandes proporciones en el continente, lo cual conducirá a reflexionar profundamente sobre las regiones ganadores y perdedoras en un proceso de tal envergadura. Sin embargo, antes de llegar a este punto hay que cuestionar la viabilidad de estos proyectos, sobre el enfoque teórico-metodológico al que responden y, consecuentemente, sobre los mitos y realidades en torno a ellos.

La potencialidad de cada proyecto es diferente, sin embargo, difícilmente los territorios y las costas del continente podrán llenarse de corredores multimodales, cruces interoceánicos y puertos hubs o pivotes. Pretender lo contrario remite a enfoques dentro de las ciencias sociales que insisten en circunscribir la unidad de análisis a los límites del Estado-nación (Yocelevzky, 1999) y, por lo tanto, neutralizan o diluyen las determinaciones propias del ámbito global o, si se quiere, del sistema-mundo (Braudel, 1985; Wallerstein, 1996), creando grandes expectativas con un débil sustento tanto conceptual como empírico (Martner, 2002).

Por tanto, el objetivo de este trabajo consiste en aportar elementos de análisis para determinar la potencialidad e impacto de las principales propuestas y proyectos de corredores multimodales ${ }^{1}$ e interoceánicos en Norte y Centroamérica, desde una perspectiva teórica estructural-sistémica, que pone énfasis en las determinantes geoeconómicas y geopolíticas de un mundo crecientemente globalizado. Como hipótesis principal se plantea que la posibilidad de desarrollar corredores multimodales y bioceánicos en esta región está determinada principalmente por la nueva red global de los flujos comerciales y por la localización de los principales ejes de transporte marítimo internacional, cuya zona de influencia (binterland) puede expandirse en la medida en que se alcance mayor integración de los sistemas de transporte multimodal asociados a redes productivas globalizadas.

El presente artículo se estructura en cuatro apartados principales. En el primero se establece el enfoque conceptual sobre el

\footnotetext{
${ }^{1}$ Cabe señalar que el término multimodalismo esta relacionado estrechamente con la tecnología del contenedor, misma que revolucionó el transporte internacional al permitir eliminar la ruptura de carga y propiciar las redes integradas de transporte "puerta a puerta". Por eso los corredores multimodales aquí analizados tienen que ver con el movimiento masivo de mercancías en contenedores.
} 
cual se abordará la temática de la conformación de los corredores multimodales. En el segundo se analiza, de manera somera, el impacto del cambio de centralidad y la reciente reestructuración de la economía-mundo capitalista en la dinámica de los flujos de mercancías y en la conformación de los principales ejes de transportación internacional. Aquí se hace hincapié en las implicaciones que tiene el predominio de los flujos transpacíficos para el desarrollo de corredores multimodales de transporte internacional en Norte y Centroamérica. En el tercero, se analiza el comportamiento de los principales corredores multimodales y cruces interoceánicos vigentes en el Hemisferio Norte del continente americano. En esta sección es inevitable determinar la posición y las implicaciones que tienen los puentes terrestres estadounidenses y el Canal de Panamá en el flujo de bienes relacionados con esta parte del mundo. En el cuarto apartado se realiza una evaluación preliminar de los principales proyectos de corredores multimodales e interoceánicos en México y Centroamérica, determinando las potencialidades y límites más evidentes a la luz de un enfoque que centra el análisis en las determinaciones de redes y corredores de transporte que responden crecientemente a las necesidades de la producción-distribución de actores que operan en cadenas globalizadas. Por último, se plantean las conclusiones preliminares donde se destacan las aportaciones conceptuales, metodológicas y prácticas de este enfoque y se dejan abiertas vertientes de análisis en un tema que apenas comienza a ser explorado.

\section{Una aproximación conceptual al tema de los corredores multimodales}

El presente trabajo se apoya en buena medida en la conceptualización de un nuevo paradigma socioterritorial, cuyo elemento distintivo se encuentra en el planteamiento del espacio de redes y flujos de la globalización. Durante la década de los noventa, destacados investigadores en el campo del análisis socioespacial y geográfico (en sus vertientes regional, económica, política y humana), tales como Pierre Veltz (1999), Manuel Castells (1997), Daniel Hiernaux (1999), Saskia Sassen (2003), Inmaculada Caravaca (1998), Ricardo Méndez (2002) y Milton Santos (2000) entre otros, incluyen parcial o totalmente el enfoque estructural-sistémico de los sistemas mundiales de Braudel (1985) y Wallerstein (1996), con la finalidad de diseñar un enfoque teórico- 
metodológico para interpretar las nuevas configuraciones territoriales y las dinámicas socioespaciales de la globalización.

Un aporte sustancial bajo este enfoque consiste en ubicar la unidad de análisis en la conformación de un espacio global (al estilo del sistema-mundo capitalista de Wallerstein) que se articula crecientemente a través de redes y flujos materiales e inmateriales (Castells, 1997; Martner, 2001). Tal traslado de la unidad de análisis, poco valorado y comprendido por la corriente económica dominante (de corte neoclásica y neopositivista), permite revelar estructuras, configuraciones, dinámicas y tendencias que pasan inadvertidas para los países y las regiones y, por tanto, no son consideradas a la hora de establecer políticas públicas de desarrollo de infraestructura y tecnología.

Un ejemplo evidente de tal desconsideración es la multiplicación de proyectos para construir grandes obras de infraestructura de transporte (corredores internacionales, megapuertos, megaterminales, etc.) en cada uno de los países de Latinoamérica, cuestión que surge de manera casi natural cuando se ubica la unidad de análisis en el Estado-nación o en escalas menores, dentro de un entorno de incremento de los flujos debido a la apertura comercial y la globalización en curso. Sin embargo, más allá del dato evidente, esto impide visualizar una estructura más profunda, como la configuración de una red y un espacio global de flujos, cuya lógica de funcionamiento no es la misma que la de los Estados nacionales, puesto que, como señala Hiernaux (1993), la globalización de los procesos productivos y sociales "no requiere el control del espacio continuo para operar, logra su expresión en puntos selectos - place o lugares a la Giddens- " (Hiernaux, 1993: 9).

En este sentido, Castells, define el espacio de redes y flujos de la globalización como "la organización material de las prácticas sociales compartidas simultáneamente en el tiempo, las cuales operan a través de flujos" (Castells, 1996: 412). Por flujos entiende "la efectiva, repetitiva y programable secuencia de intercambio e interacción entre lugares físicamente separados, articulados por actores sociales en la economía, la política y la estructura simbólica de la sociedad" (Idem).

Este nuevo referente teórico rompe con dos propiedades fundamentales en el análisis espacial previo. En efecto, la resistencia física a los cambios y la ordenación territorial según la distancia "se ven eclipsadas, cuando tiempo y espacio son a la vez más sincrónicos y menos jerarquizados” (Caravaca, 1998: 9). En otros términos, se reduce la importancia de la distancia como forma de 
caracterización del espacio y lo que tiene que valorisarse ahora es la cualidad de la conexión e integración de los fragmentos espaciales selectos en una red espacial globalizada. En otras palabras, las relaciones de proximidad y de cohesión geográfica entre un centro y sus áreas periféricas contiguas ahora tienden a desestructurarse por la emergencia de un territorio de redes (Veltz, 1999) o espacio de flujos (Castells, 1997), donde predominan las relaciones entre nodos fragmentados y territorialmente discontinuos que, sin embargo, se articulan, aun a largas distancias, con el apoyo de las recientes innovaciones tecnológicas, principalmente en las comunicaciones y los transportes.

Así las cosas, Caravaca señala que "El espacio de flujos ${ }^{2}$ se convierte, pues, en referente central de las lecturas e interpretaciones sobre la emergencia y consolidación de nuevas formas y dinámicas territoriales basadas en la existencia de redes. Dichas redes, controladas por los grupos [actores] que detentan el poder y ejercen las funciones de dirección, cambian de manera constante, organizando el espacio en función de la posición que ocupan en ellas los distintos lugares" (Caravaca, 1998: 9).

Ahora bien, las redes que conforman el espacio de flujos castelliano no son de un solo tipo. Éstas pueden corresponder tanto a la actividad financiera como a otras expresiones del capital y de la organización socioespacial. Por ejemplo, la producción industrial fragmentada requiere uniones entre operaciones ubicadas en diferentes lugares, por tanto, los flujos de productos y de información entre firmas circulan por determinados nodos y hubs de la red global. Estos nodos y hubs también tienen diferentes características. En algunos predominan fases complejas del proceso de circulación del capital-dinero, en otros, son más significativas las fases de producción-distribución del capital-mercancía, de la gestión de inventarios e información.

Precisamente la contribución conceptual de este trabajo consiste en incorporar, dentro del enfoque estructural-sistémico del espacio de redes y flujos, categorías de análisis de una red física peculiar del espacio global, el corredor multimodal, mismo que funciona como eje de articulación técnico y espacial frente a la fragmentación de las cadenas de producción-distribución propia de esta fase de globalización capitalista.

\footnotetext{
2 "La teoría del espacio de flujos comienza con el reconocimiento implícito de que las sociedades están organizadas asimétricamente en torno a los intereses dominantes específicos de cada estructura social [...] Pero tal dominación no es puramente estructural. Es propiciada, sin duda concebida, decidida e implementada por actores sociales" (Castells, 1996: 415).
} 
El corredor multimodal no debe confundirse con un corredor de transporte convencional, donde no hay más función que el desplazamiento de vehículos cargados de mercancías sobre la infraestructura, las terminales y vías de comunicación de determinado territorio. Por el contrario, el corredor multimodal requiere de una serie de servicios, terminales especializadas, tecnologías y regulaciones para desarrollar las actividades de valor agregado que demandan las formas de producción-distribución de un creciente número de firmas manufactureras y de servicios, basadas en cadenas de suministro justo a tiempo que operan con inventarios mínimos y cuyos estándares de calidad, certeza y sincronía en las operaciones de movilidad y distribución son variables más importantes que el coste de transporte dentro de su circuito logístico completo. ${ }^{3}$

Así, la necesidad de generar fluidez y flexibilidad para la integración de las cadenas productivas globalizadas demanda del corredor multimodal una serie de atributos físicos, tecnológicos, operativos y organizativos como el desarrollo de zonas de actividades logísticas, con terminales especializadas de contenedores, centros de consolidación de contenedores, formación de lotes, cruce de andén (cross dock) y plataformas de distribución, así como con los llamados recintos fiscalizados estratégicos. ${ }^{4}$ A ello se suma la introducción de plataformas compartidas de procesos de información y documentación donde participan actores con el conocimiento y el saber hacer especializado para la atención de los flujos de carga y de los sistemas de transporte multimodal.

En este sentido, la categoría de corredor multimodal se acerca más al concepto de corredor comercial planteado en el excelente trabajo de L. Boske y J. C. Cuttino (2003), no obstante, hay que señalar al menos un par de diferencias conceptuales. En primer lugar, el corredor multimodal, propio de la globalización, no supone solamente la presencia de actividades e infraestructura comercial, sino también de actividades de transformación o incorporación de valor en el bien movilizado, es decir, de procesos de

${ }^{3}$ En efecto, estos aspectos cualitativos de integración del transporte tienen mayor peso en la competitividad de la cadena productiva globalizada, dado que permiten ahorros importantes en inventarios, en la eficiencia de las líneas de producción, en la oportunidad con que se accede a los mercados, en la certeza y satisfacción de los clientes, etcétera.

${ }^{4}$ Esta figura legal, introducida recientemente en México, no sólo permite las actividades de almacenamiento, envasado, embalaje, acondicionamiento y distribución, sino también las actividades de transformación de los bienes e insumos para su posterior venta dentro o fuera del territorio nacional, previo pago de los impuestos correspondientes. 
la esfera de producción que se han externalizado y desplegado sobre el territorio (el corredor), desdibujando las fronteras tradicionales entre lo industrial y lo comercial, entre la producción y la distribución (Veltz, 1999). En segundo lugar, el corredor multimodal es básicamente un corredor de contenedores, no de mercancía suelta, carga a granel o commodities. En efecto, el contenedor es el elemento tecnológico característico del transporte multimodal dado que permite la integración efectiva de los modos de transporte, evitando las rupturas de carga. Es decir, el contenedor puede viajar indistintamente en barco, tren y camión, ${ }^{5}$ sin necesidad de abrirlo o descargar su contenido en los puntos de transferencia de los modos de transporte, gracias a la innovación tecnológica tanto de los vehículos, como de las terminales especializadas donde se realiza tal transferencia. Son precisamente estas características las que permiten al transporte multimodal ajustarse a las demandas de inventarios y cadenas de suministro justo a tiempo de las empresas manufactureras globalizadas.

Por último y antes de concluir este apartado, es necesario mencionar la existencia de otro enfoque conceptual, sustentado en la teoría económica neoclásica, que analiza, aunque no específicamente el tema de los corredores multimodales, las vinculaciones entre aglomeraciones urbanas, así como los cambios en la geografía económica, atribuidos de manera muy significativa a los costes de transporte. En este sentido, destacan las aportaciones de la llamada "nueva geografía económica", donde los trabajos de Krugman $(1991,1997)$ y Fujita, Krugman y Venables (2000), entre otros, ponen en escena la variable espacial (normalmente no considerada en la corriente dominante de la economía), misma que les permite destacar la interacción entre los rendimientos crecientes, los costes de transporte y el desplaza-

${ }^{5}$ El transporte multimodal y, por ende, los corredores multimodales no implican necesariamente la suma de todos los modos de transporte (barco, camión, tren, avión). De hecho, no puede haber realmente multimodalismo entre el transporte aéreo y el marítimo o ferroviario puesto que no hay una compatibilidad tecnológica ni operativa entre el contenedor de barco o tren, cuya dimensión mínima es de 20 pies de largo (1 teu) y su dimensión más usada es la de 40 pies (2 teus), frente al contenedor aéreo cuyo tamaño máximo es de 9 pies de largo y tiene menor altura. Necesariamente tendría que haber una ruptura de carga para transbordar en múltiples contenedores aéreos las mercancías de cada contenedor de tren o buque. En realidad, el transporte aéreo sólo alcanza un multimodalismo efectivo con el transporte carretero. Además, el transporte aéreo, según diversos estudios (Sánchez et al., 2003; Herrera et al., 2005), mueve menos de $1 \%$ de la carga internacional. 
miento de los factores productivos mediante la formalización y modelización matemática de tales relaciones (Fujita et al., 2000).

No obstante, se trata de una visión notoriamente economicista del espacio, donde se hace tabla rasa de las diferencias socioterritoriales, históricas y geopolíticas de los lugares, omitiendo las condicionantes propias de las relaciones de poder y de cooperación entre actores globales, estatales, regionales y locales que configuran dinámicas y aspectos cualitativos muy importantes en el desarrollo regional. ${ }^{6}$ En otras palabras, se trata de una visión mecanicista donde el espacio es un elemento pasivo, un dato (entendido básicamente como distancia) siempre traducible en forma directa e inmediata a costes y precios (Coq, 2003: 125) que afecta a individuos (empresas) cuya racionalidad económica es idéntica en cualquier lugar o región, pues siempre se comportan como homo economicus (hipótesis de la racionalidad absoluta de los sujetos). Así, la base epistemológica de la llamada nueva geografía económica se encuentra en el individualismo metodológico propio de la teoría neoclásica (Hogdson, 1998), donde la unidad elemental de análisis es el individuo (o empresa) y cuyas leyes manifiestan un principio general de comportamiento expresado en la hipótesis de una racionalidad absoluta, en tiempo y espacio, para el conjunto de las individualidades (agentes económicos).

Frente a este reduccionismo economicista, el enfoque del espacio de redes y flujos considera que la evolución de lo social no puede reducirse a la suma de los comportamientos individuales, por lo tanto, la localización de las actividades productivas se entiende como el resultado de fuerzas sociales complejas (Coq, 2003), donde evidentemente los individuos intervienen y toman decisiones, pero los mecanismos de toma de decisiones de los actores se encuentran condicionados por una evolución histórica, por un desarrollo organizativo, por la posición en la división internacional del trabajo y en el sistema mundo, por las condicionantes políticas o geopolíticas, etc. Es decir, estamos frente a una racionalidad situada, no absoluta, donde el territorio aparece como una variable activa, no pasiva.

\footnotetext{
${ }^{6}$ Las dinámicas internas e interacciones establecidas entre los actores económicos locales, las administraciones públicas, los centros de investigación y desarrollo, las instituciones de financiamiento, etc., dan lugar a procesos de aprendizaje, difusión e intercambio de conocimientos, desarrollo de la cooperación interempresarial y de redes regionales socioinstitucionales que generan territorios o regiones innovadoras, transformando la geografía económica de manera significativa, como atestiguan los trabajos de Veltz (1999), Méndez (2002), Caravaca et al. (2005), entre otros.
} 
Así, desde la perspectiva epistemológica, el enfoque del espacio de redes y flujos es de tipo holista y sistémico. Holista en el sentido de que el todo es más que la suma de las partes. Sistémico porque no se parte de esquemas de causalidad simple sino que se considera el conjunto de relaciones relevantes (económicas, sociales, territoriales, geopolíticas) y sus interacciones (Coq, 2005).

\section{Centros económicos de la globalización y flujos de mercancías}

\subsection{La dinámica de los flujos en la fase de globalización}

El sistema mundial capitalista, desde sus albores en el siglo XVI, ha requerido de centros territoriales o regiones desde los cuales ejerce su hegemonía sobre zonas subordinadas (semiperiféricas y periféricas). Sin embargo, como se trata de un sistema dinámico donde la hegemonía no es permanente, hay procesos de disputa por la centralidad que conducen a reacomodos, permitiendo el surgimiento de nuevos centros económicos, políticos y militares, así como la decadencia de regiones que otrora aparecían como lugares dominantes dentro de la geografía planetaria. Braudel (1986) y posteriormente Wallerstein (1996) han desarrollado ampliamente el tema de las oscilaciones y el desplazamiento geopolítico y económico de los centros, sus semiperiferias y periferias durante el desarrollo de tal sistema mundial.

De manera muy esquemática, se considera que en la primera etapa, llamada de capitalismo mercantil, el centro del sistema mundial se localizó en las ciudades-Estado del Mediterráneo, pero en el siglo XVII la región hegemónica se desplazó hacia el norte de Europa, específicamente hacia los llamados Países Bajos, en tanto el Mediterráneo caía en un prolongado estancamiento económico, político y comercial. Durante el siglo XVIII, con el desarrollo de la segunda etapa de expansión capitalista, conocida como capitalismo industrial, el centro del sistema se desplaza hacia Gran Bretaña, cuya hegemonía política, económica, comercial y militar perdura hasta las postrimerías del siglo XIX, donde se produce una nueva descentración ${ }^{7}$ del sistema y una fuerte disputa por la hegemonía entre países europeos como Alemania, Francia, la decadente Inglaterra y una nueva nación

${ }^{7}$ Este término se refiere al desplazamiento paulatino de un centro que comienza su declive hacia uno o varios centros emergentes que le disputan su posición (Wallerstein, 1996; Braudel, 1986). 
con creciente poderío económico y militar, localizada en el norte del continente americano. Es precisamente esta última, Estados Unidos de América, quien asume la centralidad del sistema mundial durante el siglo Xx, en la etapa conocida como capitalismo monopolista (Méndez, 1997).

Hacia finales del siglo xx, la acelerada expansión de las relaciones capitalistas, apoyada en un sustantivo proceso de cambio tecnológico que pretende abrir nuevas vías para la valorización del capital, mediante la innovación de las formas de producción, circulación y distribución de mercancías a escalas geográficas cada vez mayores, propició un nuevo proceso de descentración del sistema mundial, generando una nueva etapa conocida como capitalismo global (Méndez, 1997) que hasta el momento se caracteriza, en lo económico y comercial, por una tripolaridad constituida por la Comunidad Europea, Norteamérica y el Lejano Oriente (Japón y los países del noreste y sudeste asiático).

Desde luego, con el cambio de fase y de centralidad hay un reacomodo en la semiperiferia y periferia del sistema mundial. De acuerdo con Braudel $(1953,1986)$ y Wallerstein $(1992,1996)$, las relaciones económicas y comerciales del nuevo centro (o los nuevos centros) implican que los vínculos con ciertas regiones se vuelven más relevantes, se incorporan nuevas áreas, mientras que otras pierden presencia en el concierto internacional. Al respecto, Froebel (1980) y Storper y Harrison (1994) señalan una modificación sustancial de la división internacional y espacial del trabajo. Sin embargo, lo que normalmente ha quedado fuera del análisis de las modificaciones en la hegemonía del sistema-mundo capitalista es el estudio de la nueva geografía de los flujos y del transporte, así como la formación de nuevas rutas y corredores cuyo efecto en la estructuración del territorio de las regiones periféricas ha sido significativo. Precisamente este trabajo pretende contribuir al análisis de la nueva lógica de los flujos y sus implicaciones territoriales en la formación de corredores multimodales e interoceánicos en Norte y Centroamérica.

Para entender la dinámica de los flujos no basta con establecer las regiones centrales y sus zonas subsidiarias, también se requiere analizar el rol geoeconómico que asume cada uno de los nodos principales del centro y la periferia, así como los tipos de flujos que generan y atraen, en especial en esta etapa de globalización caracterizada por la intensificación de la movilidad de las mercancías. En efecto, la globalización de los procesos productivos ha fomentado la intensificación de los flujos de mercancías a escala planetaria, puesto que propicia la fragmentación 
espacial de la producción en la búsqueda de ventajas para cada una de las fases del proceso de fabricación de un producto. Paralelamente, las innovaciones tecnológicas recientes, sobre todo en los medios de comunicación y transporte, apoyan este proceso de desconcentración productiva.

El comercio internacional se ha transformado crecientemente en desplazamiento de bienes entre plantas de la misma corporación (flujos intrafirma) o entre el gran consorcio multinacional y sus subcontratistas internacionales que elaboran partes o insumos del producto final, para lo cual fue necesario implementar extensas redes que se desdoblan sobre espacios selectos del planeta, estructurando las nuevas relaciones de la economía-mundo, en lo que Castells (1996) ha llamado el "espacio de flujos" que se sobrepone a los vínculos de continuidad y cercanía de los espacios tradicionales, al integrar nodos territoriales, ampliamente separados en tiempo y espacio, en una red de producción-distribución globalizada que puede operar de manera simultánea e integrada.

Ahora bien, la intensificación de los flujos no ha implicado un crecimiento de las actividades económicas y el comercio internacional de igual intensidad en todas las regiones. Datos recientes del Banco Mundial (2003) muestran que tres regiones continentales, ubicadas en torno a los paralelos 30 y 60 del hemisferio norte, concentraron $82 \%$ de PIB mundial. Se trata lógicamente del noreste asiático, Norteamérica y la Comunidad Europea. Este alineamiento geográfico en torno a ejes este-oeste en el hemisferio norte tiene determinantes profundos en torno a la configuración espacial de los flujos y la conformación de corredores multimodales, que serán abordadas posteriormente.

Por lo pronto, cabe señalar que dentro de los tres bloques económicos principales hay funciones diferenciadas que reflejan una reestructuración de la división internacional del trabajo en la fase de la globalización. El Lejano Oriente (noreste y sudeste asiático) se ha convertido en el principal centro de producción mundial de bienes manufacturados, mientras que Norteamérica, en especial Estados Unidos, aparece como el principal centro de consumo. Esto ha implicado, en las últimas décadas, una intensificación de los flujos comerciales transpacíficos con un componente peculiar de desbalance de los flujos que se expresa en barcos llenos de contenedores con mercancías hacia Norteamérica y barcos semivacíos desde Norteamérica hacia el Lejano Oriente.

Por su parte, Europa también aparece como un dinámico centro de consumo mundial, aunque también se mantiene como un 
importante generador de producción mundial, por eso sus flujos aparecen menos desbalanceados que los norteamericanos. Frente a estos dos bloques (el europeo y el norteamericano), el asiático aparece como el vértice de la producción industrial mundial y del comercio global de bienes manufacturados. En efecto, se ha convertido en el verdadero generador de la fabricación de bienes manufacturados intermedios y de consumo, ligados a las cadenas productivas globalizadas y movilizados en contenedores por los sistemas de transporte multimodal internacional.

En el año 2002, los flujos transpacíficos de carga contenerizada entre Asia y Norteamérica se acercaron a los 12 millones de teus ${ }^{8}$ llenos, seguidos por los flujos de contenedores entre Asia y Europa, vía el Océano Índico y el Canal de Suez, con 10.33 millones de teus llenos, mientras que los flujos transatlánticos entre Europa y Norteamérica en la actualidad tienen el tercer lugar en importancia dentro de los flujos mundiales de contenedores, con 6.52 millones de teus llenos en el año de referencia.

\section{Figura I}

Movimiento de contenedores por bloques económicos, 2002 (millones de teus)

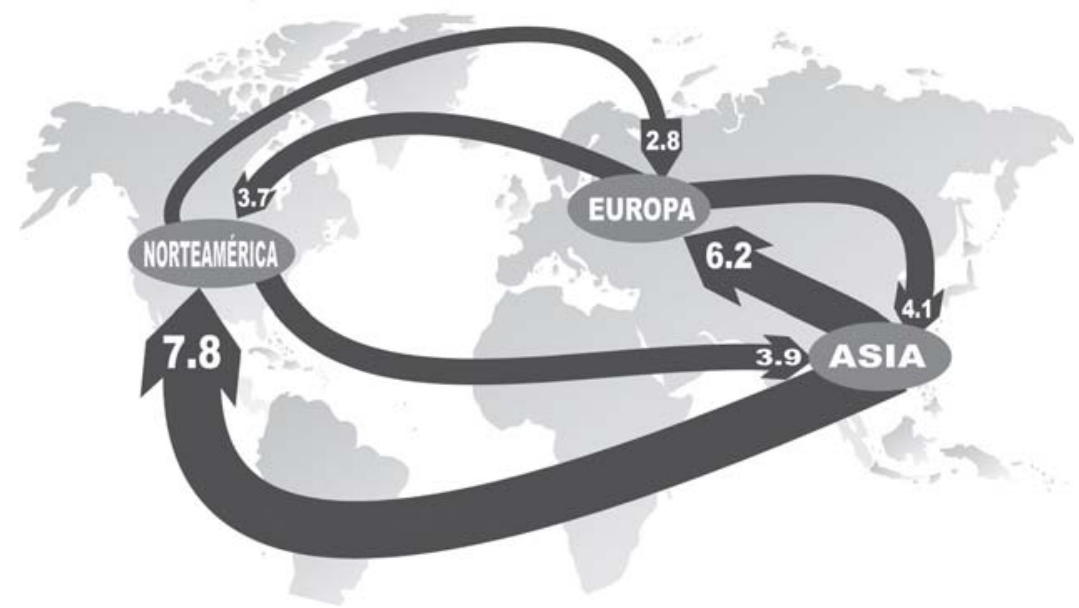

Fuente: Elaboración del IMT con base en datos de Containarisation International. Reino Unido, 2003.

${ }^{8}$ Teu (twenty equivalent units) es la unidad de medida universal y estándar para los contenedores y equivale a la unidad de medida original del contenedor marítimo de 20 pies de largo. 
Así, entre estas tres regiones continentales fluye un elevado número de mercancías, por tanto, los movimientos noreste-noroeste adquieren gran densidad y concentran los mercados de transporte más importantes del mundo. Efectivamente, en el año 2002, 67\% de los contenedores se movieron en dirección esteoeste, en torno a los paralelos 30 y 60 del hemisferio norte, con orígenes y destinos entre los tres bloques económicos principales, mientras que el 33\% restante correspondió a flujos nortesur, entre países periféricos y países centrales de la economíamundo capitalista.

En todo caso, aquí no hay que dejar pasar una observación acerca de la concentración relativa de los flujos de mercancías. De hecho, ésta es claramente menor que la concentración de la riqueza medida a través del PIB. Más aún, si sumamos la participación del movimiento de flujos de mercancías de China, que mayoritariamente se mueven en el eje este-oeste del hemisferio norte, a la participación de los otros países no centrales o periféricos en la economía-mundo, este grupo alcanzaría $43 \%$ de los flujos mundiales de manufacturas transportadas en contenedores, frente al $57 \%$ de lo movilizado entre los tres polos dominantes.

Está claro que los procesos de liberalización económica y de apertura comercial han permitido modificar notoriamente la división internacional y espacial del trabajo mediante la desconcentración/fragmentación de fases de los procesos de producción, distribución y servicios hacia lo que Sassen (2003) llama el Sur Global, y otros autores definen como regiones o territorios no centrales, integrados a las cadenas de producción-distribución globalizadas (Castells, 1996; Hiernaux, 1993; Martner, 2001). Así, encontramos una dispersión o desconcentración relativa de fases y actividades, pero no de la riqueza, pues el PIB mundial sigue concentrado en los países y regiones de los tres polos dominantes (la tríada del poder, como le llama Ohmae).

"La geografía de la globalización contiene tanto una dinámica de dispersión como una de centralización", dice Sassen (2003: 7). En efecto, las innovaciones tecnológicas recientes en comunicaciones y transporte permiten gestionar la relativa dispersión de fases y actividades, sin perder el control centralizado de las cadenas de valor corporativas, propias de un sistema desigual y asimétrico de apropiación de la riqueza, que establece redes jerárquicas para operar globalmente. 


\subsection{El predominio de los flujos transpacíficos}

La Cuenca del Pacífico abarca un espacio inmenso donde convergen decenas de países de Asia, América y Oceanía, por lo que su análisis se vuelve muy complejo, salvo si se jerarquizan los vínculos comerciales transpacíficos y se detectan las principales rutas y corredores multimodales en esta zona del planeta.

De acuerdo con Cueva, "en 1960, el comercio de Estados Unidos con Asia representaba menos de la mitad del comercio estadounidense con Europa. En 20 años, el volumen total destinado a Asia terminó por desplazar al comercio con todo el continente europeo. En 1986, el comercio transpacífico de Estados Unidos superaba en 50\% el comercio con Europa Occidental. Estados Unidos y Canadá realizaban a principios de los años noventa un volumen de comercio en el mercado del Pacífico superior al que mantenían con sus socios tradicionales de Europa. Japón se convirtió en el segundo socio comercial de Estados Unidos, después de Canadá. El desequilibrio comercial de Estados Unidos tiene que ver principalmente con el intercambio con las economías asiáticas" (Cueva, 1997: 281).

Cabe señalar que, con el advenimiento del Tratado de Libre Comercio de América del Norte (TLCAN), México se convirtió en el tercer socio comercial de Estados Unidos durante la década de los noventa. Incluso, hacia el año 2000, alcanzó el segundo lugar de intercambio de bienes con la economía estadounidense, superando a Japón. No obstante, este hecho no debilitó el vínculo traspacífico entre el Lejano Oriente y Estados Unidos, puesto que, durante la década de los noventa, los países de reciente industrialización del sudeste asiático incrementaron rápidamente sus flujos comerciales con Norteamérica. Además, la incorporación plena de China a la economía capitalista globalizada está actuando como un nuevo motor del comercio internacional. Resulta significativo el dato de que, desde el primer semestre de 2003, China pasó a ser el segundo socio comercial de Estados Unidos, desplazando a México al tercer lugar. Ante esta evidencia, la hegemonía de los flujos transpacíficos difícilmente podrá ser cuestionada en las próximas décadas.

Por otra parte, durante los últimos 30 años, para Estados Unidos "la expansión económica de la Cuenca del Pacífico y el comercio transpacífico entraña transformaciones importantes en la organización interna de la economía, dentro de su territorio nacional: se desplaza hacia el Oeste el antiguo gran polo de atracción del Este. California, en particular, tiende a convertirse en el 
puente entre la economía estadounidense y la asiática. Con el dinamismo que le confirió el Pacífico asiático, la entidad californiana se convirtió en el principal centro urbano, comercial, financiero e industrial estadounidense en los ochenta [...] El desplazamiento relativo del este por el oeste estadounidense se expresa entre otros factores por el extraordinario dinamismo de Los Ángeles, debido en parte a las inversiones japonesas, en contraste con la decadencia -relativa- de Nueva York (Cueva Perus, 1997: 283).

Aun así, cabe señalar que el este de Estados Unidos sigue concentrando a la mayoría de su población y de la actividad económica, por tanto, los flujos vinculados con el continente asiático necesitaran de la ampliación o diversificación de los corredores de transporte para atender la demanda creciente de movilidad de la mercancía.

\section{Principales corredores multimodales e interoceánicos en el hemisferio norte del continente americano}

\subsection{El corredor multimodal Asia-Estados Unidos}

Al revisar las características recientes de la geografía de los flujos de mercancías en contenedores en el hemisferio norte del continente americano, se observa una diferencia abismal en el volumen de los movimientos y, en última instancia, en el tamaño de los mercados. En la figura II se aprecia, a simple vista, tal diferencia en el orden de las magnitudes. Por ejemplo, los flujos de contenedores del corredor que converge en los puertos de la costa del Pacífico estadounidense (Costa Oeste) son 22 veces más grandes que los que convergen en los puertos del Pacífico mexicano. De igual forma, los flujos de contenedores por el Atlántico estadounidense (Costa Este más puertos del Golfo de EE.UU.) son 16 veces más grandes que los flujos de los puertos mexicanos del Golfo. En la parte latinoamericana del hemisferio norte, sólo el Canal de Panamá muestra un flujo significativo de contenedores, pero 50\% de éstos corresponden al corredor de transporte entre Asia y la Costa Este de Estados Unidos, como se constatará posteriormente. A la luz de estos datos, parece que la posibilidad de desarrollar corredores multimodales internacionales pasa necesariamente por el análisis del peso que tiene el mercado estadounidense en la región.

De hecho, el principal corredor multimodal de carga en contenedores de la Cuenca del Pacífico está constituido por el eje 


\section{Figura II}

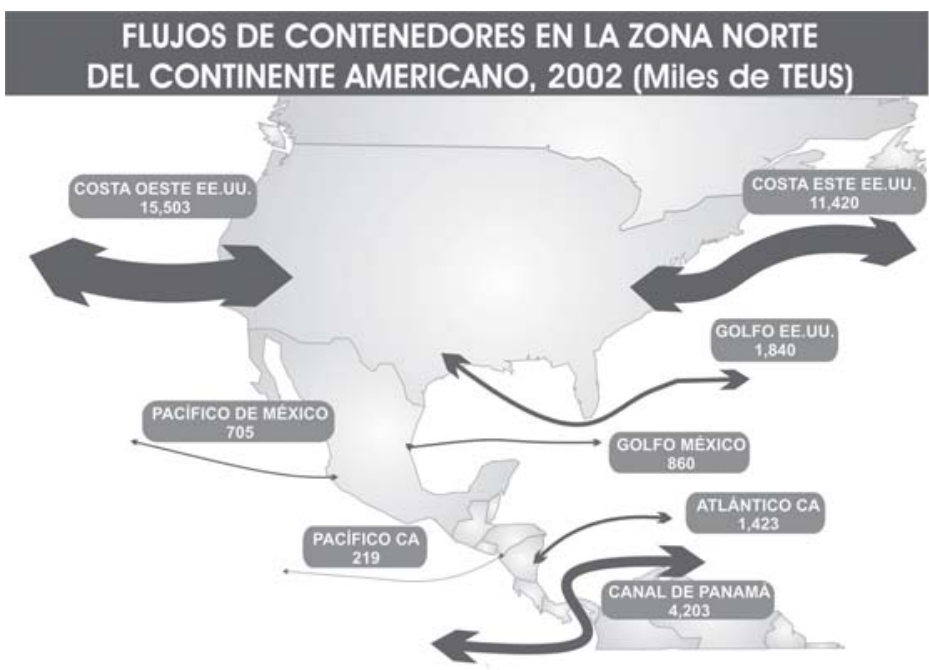

Fuente: Elaboración propia con base en datos de PIERS y CEPAL.

que vincula los puertos del Lejano Oriente (noreste y sudeste asiático) con los de la Costa Oeste de los Estados Unidos, mismos que articulan los flujos tierra adentro de aquel país (centroeste, sur-este, etc.) mediante el desarrollo de los llamados puentes terrestres ferroviarios de doble estiba de contenedores, cuya expansión ha sido vertiginosa desde la década de los noventa. Esto dio lugar al corredor multimodal más denso del mundo que vincula Asia con el centro-este de Estados Unidos (Chicago, Detroit, Saint Louis, Kansas City, Memphis, Dallas, Houston, etcétera).

Durante la década 1991-2002, tal corredor multimodal creció a una tasa promedio de $7.5 \%$ anual. A lo largo del año 2002, los puertos estadounidenses de la Costa Oeste (en el océano Pacífico) movieron más de 15.5 millones de teus (sumando contenedores llenos y vacíos), de los cuales $90 \%$ estaba vinculado a los países del Lejano Oriente, es decir, al citado corredor multimodal.

Ahora bien, cabe señalar que no todos los puertos estadounidenses de la Costa Oeste se han comportado de la misma forma durante la última década. Los datos muestran que los puertos del suroeste fueron mucho más dinámicos que los del noroeste. En efecto, mientras el hub portuario del sur de California, constituido por Los Ángeles y Long Beach, creció a una tasa promedio de 9\% anual durante la década de los noventa, en el noroes- 
te, el hub del estado de Washington, constituido por los puertos de Seattle y Tacoma, creció a un ritmo promedio de $2 \%$ anual durante el mismo periodo.

En 2001 el resultado parcial de esta tendencia se expresa en una fuerte concentración de los flujos de carga contenerizada en torno al hub del sur de California (Los Ángeles-Long Beach), que manejó $71.5 \%$ de las cajas movidas en la Costa Oeste estadounidense. En contraparte, el hub norteño (Seattle-Tacoma) redujo su participación relativa en casi 10 puntos porcentuales entre 1991 y 2001. En este último año sólo manejó 15.6\% de los contenedores de la Costa Oeste de Estados Unidos.

Sin duda, hay múltiples razones para este reacomodo geográfico del corredor Lejano Oriente-Costa Oeste de Estados Unidos, entre las que se destacan la creciente importancia económica de la zona metropolitana de la ciudad de Los Ángeles, el desarrollo de infraestructura especializada, centros de distribución y sistemas automatizados de información por actores gubernamentales y empresas globales vinculadas a la transportación marítima y multimodal internacional, así como la consolidación del principal eje multimodal en la geografía estadounidense, constituido por el puente terrestre de doble estiba que conecta Los Ángeles-Long Beach con el centro-este de Estados Unidos, especialmente con Chicago, donde se localiza la plataforma logística de consolidación, almacenamiento y distribución más importante de aquel país y en la cual convergen todos los ejes ferroviarios de Norteamérica. Asimismo, el hub californiano ha establecido una articulación creciente con las terminales intermodales del estado de Texas, cuya función como plataformas para la distribución para el este y para México adquiere mayor relevancia en la zona TLC.

Por su parte, los puentes terrestres de doble estiba, que atraviesan el territorio estadounidense de oeste a este, siguen una dinámica similar a la de los puertos de la Costa Oeste. En 1991, los puentes terrestres vinculados a los hubs del noroeste (Seattle-Tacoma) y del suroeste (Los Ángeles-Long Beach) se repartían el mercado, con 38 y $47 \%$ de los contenedores, respectivamente, sin embargo, en el 2001 se observa una evidente concentración a favor del hub californiano.

Cabe señalar que el procesamiento y análisis de los datos recabados, a la luz del enfoque conceptual del espacio de redes $y$ flujos, permite visualizar y comprender de manera global la lógica estructural y la dinámica de estos corredores multimodales, 


\section{Cuadro 1}

Distribución porcentual de los contenedores transportados por los puentes terrestres ferroviarios en los hub de la Costa Oeste de Estados Unidos, 1991-2001

\begin{tabular}{|c|c|c|c|c|c|c|}
\hline$A \tilde{n} O$ & $\begin{array}{c}\text { Los } \\
\text { Ángeles / } \\
\text { Long } \\
\text { Beach }\end{array}$ & $\begin{array}{l}\text { Oakland / } \\
\text { San } \\
\text { Francisco }\end{array}$ & Portland & $\begin{array}{l}\text { Seattle / } \\
\text { Tacoma }\end{array}$ & $\begin{array}{c}\text { Total } \\
\text { puertos del } \\
\text { Pacífico }\end{array}$ & $\begin{array}{c}\text { Total } \\
\text { puertos del } \\
\text { Pacífico entre } \\
\text { total de la red } \\
\text { ferroviaria }\end{array}$ \\
\hline 1991 & 47.2 & 7.5 & 6.8 & 38.4 & 100.0 & 57.0 \\
\hline 1992 & 56.0 & 10.7 & 7.3 & 26.0 & 100.0 & 49.5 \\
\hline 1993 & 56.2 & 10.4 & 8.1 & 25.3 & 100.0 & 48.3 \\
\hline 1994 & 55.4 & 9.7 & 10.6 & 24.3 & 100.0 & 49.9 \\
\hline 1995 & 58.7 & 10.1 & 8.9 & 22.3 & 100.0 & 49.3 \\
\hline 1996 & 59.0 & 12.5 & 7.4 & 21.1 & 100.0 & 52.3 \\
\hline 1997 & 58.5 & 12.1 & 6.9 & 22.5 & 100.0 & 51.3 \\
\hline 1998 & 57.4 & 12.7 & 6.0 & 23.9 & 100.0 & 54.5 \\
\hline 1999 & 60.3 & 12.4 & 5.7 & 21.6 & 100.0 & 54.7 \\
\hline 2000 & 61.7 & 12.1 & 5.5 & 20.6 & 100.0 & 53.4 \\
\hline 2001 & 65.8 & 12.3 & 4.4 & 17.5 & 100.0 & 51.3 \\
\hline
\end{tabular}

Fuente: Elaboración del Instituto Mexicano del Transporte (IMT), con base en Surface Transportation Board, Carload WayBill Sample, Association of American Railroads.

que se están configurando y reconfigurando constantemente a partir de la intervención de actores sociales concretos.

Por lo pronto, el análisis de los datos bajo esta óptica muestra que el principal corredor multimodal transpacífico ha desplazado su centro de gravedad hacia el sur de California, lo cual reposiciona la importancia geográfica de algunos puertos mexicanos de la costa del Pacífico. Tal es el caso del puerto de Ensenada, ubicado en Baja California, a $120 \mathrm{~km}$ de la frontera con California. Ensenada no sólo se localiza cerca de los puertos estadounidenses de Long Beach-Los Ángeles, sino que también tiene cercanía geográfica con el puente terrestre que concentra una proporción cada vez mayor de los contenedores movidos por ferrocarril doble estiba en Norteamérica.

Otro elemento de suma importancia en el análisis se refiere a los orígenes-destinos de los contenedores movidos por los puentes terrestres de doble estiba dentro del territorio estadounidense. La identificación de estos lugares permite establecer los principales centros de generación, atracción y distribución de mercancías de la Unión Americana y, por extensión, reconocer la posición de los puertos mexicanos frente a ellos, en términos de distancia, de infraestructura, de equipamiento y de servicios logísticos ya existentes. 


\section{Cuadro 2}

Principales flujos de contenedores por los Puentes Terrestres ferroviarios con O-D en Los Angeles/Long Beach, California.

\begin{tabular}{|c|c|c|c|c|c|c|c|c|}
\hline \multicolumn{5}{|c|}{1991} & \multicolumn{4}{|c|}{2001} \\
\hline & $\begin{array}{cc}B E A & C \\
\text { (Condado) } & M\end{array}$ & $\begin{array}{l}\text { Contenedores } \\
\text { Miles de teus }\end{array}$ & $\%$ & ^ & $\begin{array}{c}\text { BEA } \\
(\text { Condado) }\end{array}$ & $\begin{array}{l}\text { Contenedores } \\
\text { Miles de teus }\end{array}$ & $\%$ & $\hat{\imath}$ \\
\hline 1 & Chicago & 684 & 33.5 & 33.5 & Chicago & 2,333 & 41.9 & 41.9 \\
\hline 2 & Houston & 252 & 12.3 & 45.8 & Dallas & 585 & 10.5 & 52.5 \\
\hline 3 & Nueva Orleáns & ns 238 & 11.6 & 57.4 & Memphis & 519 & 9.3 & 61.8 \\
\hline 4 & Memphis & 126 & 6.2 & 63.6 & Houston & 496 & 8.9 & 70.7 \\
\hline 5 & Dallas & 119 & 5.8 & 69.4 & Kansas City & 239 & 4.3 & 75.0 \\
\hline 6 & St. Louis & 90 & 4.4 & 73.8 & St. Louis & 120 & 2.1 & 77.2 \\
\hline 7 & Kansas City & 79 & 3.9 & 77.7 & San Antonio & 55 & 1.0 & 78.2 \\
\hline 8 & Nueva York & 40 & 2.0 & 79.6 & El Paso & 36 & 0.7 & 78.8 \\
\hline 9 & Atlanta & 36 & 1.7 & 81.3 & Atlanta & 34 & 0.6 & 79.4 \\
\hline 10 & Los Ángeles & 22 & 1.1 & 82.4 & Minneapolis & 34 & 0.6 & 80.0 \\
\hline 11 & Otras & 360 & 17.6 & 100.0 & Otras & 1,110 & 20.0 & 100.0 \\
\hline & Total & 2,046 & 100.0 & & Total & 5,561 & 100.0 & \\
\hline
\end{tabular}

Fuente: Elaboración propia con base en Surface Transportation Board, Carload WayBill Sample, Association of American Railroads, 1991 y 2001.

* BEA.- the Business Economic Area code.

Cabe señalar que en las terminales intermodales interiores también se produjo un fuerte proceso de concentración de la carga contenerizada en Estados Unidos. Durante los años noventa, Chicago se consolidó como el principal centro de atracción, generación y distribución de carga contenerizada de doble estiba manejada por los puentes terrestres ferroviarios.

En 1991, Chicago movía 33.5\% de los contenedores de los puentes terrestres con origen-destino en el $h u b$ portuario de Los Ángeles-Long Beach, mientras que para 2001, la concentración alcanzó 42\%. Otros puntos importantes que aumentaron su presencia en la última década, aunque con niveles de concentración menores, son Dallas, con 10.5\%, Memphis, con 9.3\%, Houston, con $8.9 \%$ y Kansas City, con $4.3 \%$.

La preponderancia del vínculo geográfico con Chicago es notable en todos los puertos de la Costa Oeste de Estados Unidos. Ésta representa $47 \%$ de los flujos del puente terrestre que nace en el puerto de Oakland, California, 51\% de los flujos del puente terrestre de Portland y 58\% de los movimientos origen-destino del hub Seattle-Tacoma. En estos puertos también es importante la vinculación con los nodos del centro-este (Memphis y Kansas City, principalmente) y con el estado de Texas.

En este punto es importante resaltar que el enfoque de espacio de redes y flujos permite introducir una nueva categoría de análi- 
sis, denominada hinterland de la globalización (o si se quiere, zona de influencia espacial de la globalización) para medir el alcance territorial real de los puertos, terminales y corredores multimodales. A diferencia del concepto tradicional de hinterland, caracterizado por una limitada zona de influencia territorial, de carácter cautivo (Martner, 1999), ${ }^{9}$ el hinterland de la globalización es normalmente muy extenso y de difícil delimitación, ${ }^{10}$ debido al amplio despliegue territorial aportado por los corredores multimodales (por ejemplo, los puentes terrestres de Estados Unidos) y al hecho de que siempre está expuesto a la competencia de nuevos corredores, puertos y centros de transporte.

No obstante, esta propuesta de análisis nos permite detectar, por ejemplo, que el hinterland globalizado del corredor multimodal transpacífico articulado por los puentes terrestres, cuyo vértice se encuentra en los puertos de la Costa Oeste de Estados Unidos, no suele alcanzar a las ciudades y puertos de la Costa Este sino que establece su límite en las principales ciudades del centro-este, desde Illinois hasta Texas. Esto significa que los flujos asiáticos y transpacíficos hacia las ciudades y regiones ubicadas entre el centro-este y la Costa Este caen bajo el hinterland de otros corredores multimodales, probablemente articulados por el Canal de Panamá. Así, aunque exista la infraestructura de costa a costa, en estricto sentido ésta no opera como puente terrestre, por tanto, lo que determina la dimensión espacial del corredor son los flujos y la relación socioterritorial que hay detrás de ellos, por encima de la infraestructura o el espacio construido.

\subsection{La vigencia del corredor interoceánico del Canal de Panamá}

El segundo corredor transpacífico en importancia está constituido por el eje que vincula al Lejano Oriente con los puertos de la Costa Este de Estados Unidos, vía el Canal de Panamá. Desde 1991 hasta 2002, el movimiento de contenedores por el Canal de Panamá creció a un ritmo cercano a 7\% anual, hasta superar

${ }^{9}$ El hinterland tradicional comprende sobre todo la zona aledaña a los puertos y terminales donde prácticamente no había competencia debido a las dificultades de accesibilidad por sistemas de transporte unimodales (no integrados) y, por ende, a la inexistencia de infraestructura especializada y corredores multimodales que entraran a disputar tal zona de influencia.

${ }^{10}$ Para resolver el problema de la delimitación del hinterland de la globalización se recurrió a un análisis de tipo parettiano de los datos, donde $80 \%$ o más de los flujos origen-destino determinan la zona de influencia efectiva del corredor. 


\section{Figura III}

Contenedores movidos por los puentes terrestres de la Costa Oeste de Estados Unidos, 2001 (miles de cajas)

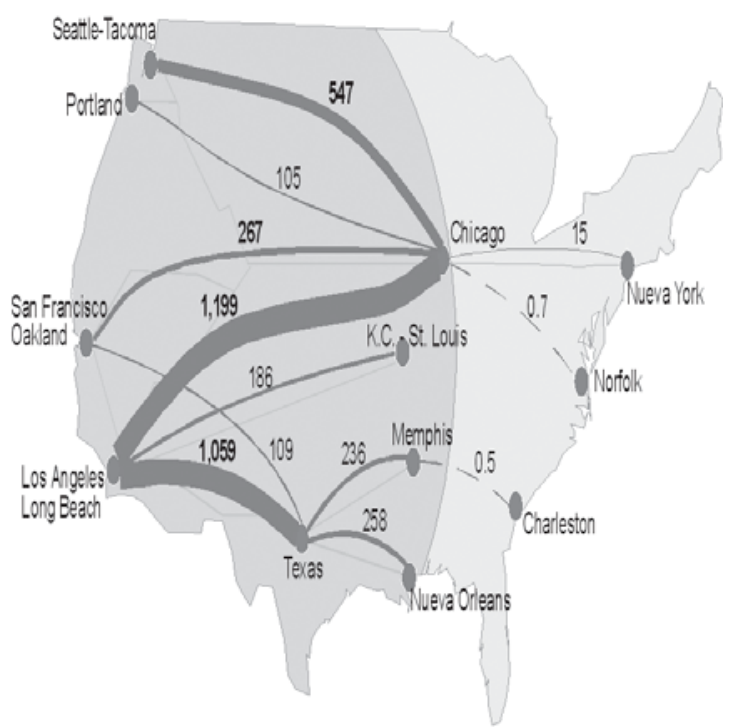

Fuente: Elaboración propia con base en Rail Waybill Data: 2000. BTS, U.S. Department of Transportation.

los 4 millones de teus en el último año de referencia. De éstos, cerca de 50\% (dos millones de teus) correspondieron al corredor Lejano Oriente-Costa Este de Estados Unidos.

Desde fines de la década de los noventa este corredor se reactiva y mantiene un gran dinamismo hasta la actualidad. Varios elementos propiciaron el renacimiento de la vía del Canal de Panamá para vincular Asia con la Costa Este estadounidense. Por una parte, la competitividad de este corredor basado en servicios todo agua (all water) aumentó sobre todo para los productos de menor valor agregado que privilegian más el costo de transportación que los apremios del tiempo derivados de las cadenas de suministro con inventarios justo a tiempo, frente al corredor que utiliza los puertos estadounidenses del Pacífico (Costa Oeste) y los puentes terrestres de doble estiba de contenedores para llegar a las ciudades de la Costa Este de Estados Unidos. Por ejemplo, se ha observado que un contenedor de 40 pies movido entre Hong Kong y Nueva York, vía el Canal de Panamá, llega a costar alrededor de 500 dólares menos si realiza el recorrido por los puertos de la Costa Oeste y los puentes terrestres, aunque 
esta última vía implica siete días menos de recorrido que la primera opción. El mayor costo relativo de los puentes terrestres para algunos destinos localizados en el este de Estados Unidos se debe a factores como el desbalance de los flujos, que se expresa en una relativa saturación del transporte marítimo, las terminales y los servicios de transporte terrestre en el sentido de la importación, mientras que en el sentido de la exportación los trenes de doble estiba y los buques regresan semivacíos, teniendo que absorber costos de operación que no logran realizarse en fletes.

Otro aspecto del mayor costo relativo de los puentes terrestres tiene que ver con la recuperación de grandes inversiones en infraestructura realizadas para ampliar la capacidad y la eficiencia de estas vías. Por ejemplo, el llamado Proyecto Alameda, que permite separar el tráfico de trenes generado por los puertos de Los Ángeles-Long Beach del tránsito y la circulación urbana de la ciudad de Los Ángeles, terminó costando 1.8 billones de dólares. Adicionalmente, los conflictos laborales entre los puertos y los sindicatos de estibadores de la Costa Oeste que, incluso, derivaron en una costosa paralización de actividades en octubre de 2002, implicaron nuevas tensiones que repercuten en ese encarecimiento relativo.

Por otra parte, no puede olvidarse el hecho de que todavía la mayor parte de los centros de producción y consumo de los Estados Unidos se localizan en su Zona Este y que, recientemente, los grandes distribuidores minoristas o retailers estadounidenses, como Wal-Mart, Kmart, Home Depot, Dollar General y Dollar Tree, entre otros, abrieron enormes centros de distribución en ciudades de la Costa Este. Por tanto, en los últimos años, estos actores se convirtieron en los principales impulsores del desarrollo de los servicios todo agua entre el Lejano Oriente y la Costa Este de los Estados Unidos, vía el Canal de Panamá.

Según Mongelluzo (2003), en el año 2001 la empresa WalMart, el mayor usuario de los servicios multimodales de carga contenerizada en el mundo, utilizó los puertos de la Costa Oeste para mover $43 \%$ de sus contenedores vinculados al movimiento asiático, proporción notablemente menor al 74\% que manejaba en 1994 por dichos puertos. El autor también señala que Savannah "ha sido quizás el puerto de la Costa Este más exitoso en la competencia por el tráfico asiático de contenedores. Este puerto del estado de Georgia mueve 30\% de las importaciones en contenedores de Wal-Mart" (Mongelluzo, 2003: 13). Otros puertos 
de la Costa Este que incrementaron su participación en los flujos asiáticos son Norfolk, Nueva York y Charleston.

Ahora bien, es preciso señalar que $70 \%$ de los contenedores de Asia siguen ingresando hacia el interior del territorio estadounidense por el corredor multimodal articulado a los puentes terrestres de la Costa Oeste, privilegiando el tiempo de recorrido y la oportuna entrega de los suministros a sus sofisticadas cadenas productivas, sobre el costo de transporte.

En todo caso, esta distribución no impide el elevado dinamismo de ambos corredores multimodales en los últimos años. Efectivamente, desde 2003, con la reactivación de los flujos de carga entre Asia y Norteamérica, los dos corredores transpacíficos muestran tasas de crecimiento anual de dos dígitos. Este acelerado crecimiento ha animado la posibilidad de corredores multimodales internacionales tanto en México como en Centroamérica. No obstante, en el ámbito de la geografía global de los flujos o, como diría Castells (1996), en el ámbito del espacio de flujos, las opciones que se proponen en el subcontinente tendrán que resultar altamente competitivas, sea en tiempo y/o en costo, frente a los corredores vigentes (puentes terrestres y Canal de Panamá), de lo contrario podríamos estar en presencia de espejismos que tan a menudo han llevado al desperdicio de los escasos recursos de la región en proyectos poco viables.

\subsection{El corredor intermodal Europa-Estados Unidos}

Aunque los flujos transatlánticos no tengan la preeminencia de los transpacíficos, el corredor de transporte entre Europa y Norteamérica mantiene una densidad significativa. De los $11.4 \mathrm{mi}-$ llones de teus que se movieron en los puertos estadounidenses de la Costa Este (Atlántico) durante el año 2002, 37\% correspondió a los flujos vinculados con Europa. Esto significa que por el corredor Europa-Norteamérica se movieron 4.2 millones de teus. Sin embargo, cerca de dos tercios de estos flujos tuvieron como origen o destino las propias ciudades de la Costa Este, por tanto, se trata principalmente de un corredor marítimo más que de un corredor multimodal. El tercio restante de los contenedores salió o entró a ciudades del este o centro-este de Estados Unidos, sobre todo a Chicago, por lo que en este caso se requirió de la conexión intermodal de los puentes terrestres de doble estiba de contenedores.

En ambas vertientes, los flujos de contenedores entre Estados Unidos y Europa prácticamente no tienen ninguna posibilidad de 
ser atraídos por los nuevos corredores intermodales en México y Centroamérica, puesto que son movimientos dentro de la Cuenca del Atlántico, en latitud norte, entre la costa occidental europea y la Costa Este estadounidense, donde prácticamente no se observan flujos interoceánicos destinados a la Costa del Pacífico norteamericano. El volumen residual de contenedores entre Europa y la Costa Oeste de Estados Unidos se mueve tanto por el Canal de Panamá como por los puentes terrestres, vía Houston.

\section{Los nuevos corredores multimodales de México y Centroamérica: integración global y viabilidad regional}

La intensificación de los flujos de mercancías en la globalización y la preponderancia que está adquiriendo el contenedor en el desarrollo de densas redes internacionales de transporte que acercan mercados y fragmentos territoriales distantes, ha generado grandes expectativas en México y Centroamérica para desarrollar corredores multimodales e interoceánicos, los cuales eventualmente activarían economías locales y ayudarían a esta región a integrarse en el espacio de redes y flujos de la globalización. Las expectativas aumentaron por el hecho de que el comercio internacional ha crecido 2.5 veces más rápido que el PIB mundial durante la última década, debido a la fragmentación y flexibilización de los procesos productivos así como a los procesos generalizados de apertura comercial. En este contexto, los pronósticos de demanda de carga muestran que entre 2012 y 2015 se duplicará el movimiento de contenedores en torno a los puertos de Centro y Norteamérica, al pasar de 20 millones de teus, en el año 2000, a 40 millones, entre 2012 y 2015, de acuerdo con dos escenarios, uno conservador y otro optimista (Piers, 2002).

Dentro de esta dinámica, el llamado Acuerdo de Concertación para el Desarrollo de los Corredores Multimodales (2004) activó los subcomités y grupos de trabajo de los siguientes corredores multimodales internacionales a través de puertos mexicanos:

- Lázaro Cárdenas-Pantaco-Nuevo Laredo

- Manzanillo-Nuevo Laredo

- Ensenada-frontera norte

- Salina Cruz-Coatzacoalcos

Se trata de evaluar y concertar el mejoramiento de la operación de los corredores con los distintos actores y promocionar el potencial de desarrollo con los operadores globales de transpor- 
te, cuyo concurso es imprescindible en la formación del espacio de flujos de la globalización.

Por su parte, en cada país de Centroamérica se han generado ideas y proyectos para la conformación de cruces multimodales interoceánicos, entre el Pacífico y el Atlántico, llamados canales secos. Incluso, no han faltado proyectos de desarrollo de un nuevo canal acuático en la región que competiría con el Canal de Panamá por los flujos marítimos de mercancías.

Con el objeto de conocer el grado de madurez de las principales propuestas de corredores multimodales e interoceánicos en la región, en los siguientes apartados se realizará un primer acercamiento mediante un planteamiento analítico que considere las determinantes del espacio de redes y flujos de la globalización, cuya configuración es fundamental en la viabilidad de tales proyectos.

\subsection{Alternativas de corredores intermodales mexicanos}

\subsubsection{El corredor multimodal del Istmo de Tehuantepec}

En México, el Istmo de Tehuantepec es la franja más estrecha y menos sinuosa entre el Océano Pacífico y el Golfo de México (Atlántico), por lo que desde hace siglos ha sido objeto de diversos proyectos para convertirlo en un eje internacional de transporte interoceánico. Ubicado en el sureste del país, donde convergen tres estados con altos grados de marginación y pobreza (Oaxaca, Chiapas y el sur de Veracruz), cuenta con dos puertos de altura (Salina Cruz, en el Pacífico, y Coatzacoalcos, en el Golfo de México), una línea ferroviaria y una carretera transístmica que conectan a ambos puertos entre sí.

Durante más de un siglo esta región ha sido considerada importante desde el punto de vista de la geopolítica continental y, por tanto, tiene muchos elementos complejos y ricos para el análisis territorial, económico, político y geográfico. El tema suscita gran controversia en el país porque la construcción del corredor supondría la rápida transformación de esta región en un espacio global. Sin embargo, hasta el momento la discusión se produce casi exclusivamente en el ámbito de la política económica y la soberanía nacional y, en muchos casos, se trata de retóricas circulares que conducen al punto de partida, sin aportar elementos nuevos al debate. Sin omitir el fuerte contenido geopolítico que conlleva el tema, se requiere avanzar en otros ámbitos de análisis, como los relacionados con el desarrollo regional y la geogra- 
fía de los transportes que, por cierto, tiene particular incidencia en este lugar.

En esta última vertiente de análisis destaca la aportación de investigadores del Instituto Mexicano del Transporte (2002, 2003) para determinar la potencialidad preliminar de dicho corredor en el contexto de la nueva configuración de las redes de transporte internacional. Al aplicar el análisis del hinterland de la globalización a los datos recabados en tales trabajos, se encuentra que:

- El eventual desarrollo del corredor del Istmo de Tehuantepec competiría de forma espacialmente diferenciada con las regiones y mercados atendidos por los corredores multimodales estadounidenses (puentes terrestres) y el Canal de Panamá.

- Por una parte, disputaría con los corredores multimodales asociados a los puentes terrestres los flujos transpacíficos de contenedores desde y hacia el centro-este y centro-sur de Estados Unidos, incluyendo las regiones de los Grandes Lagos, el Río Mississippi y el Golfo de México.

- Por otra, competiría con el Canal de Panamá por los flujos cuyo destino son las ciudades de la Costa Este de Estados Unidos (Nueva York, Filadelfia, Boston, Baltimore, Nofolk, Charleston, etcétera).

Para que sea viable, las rutas del corredor del Istmo de Tehuantepec requerirían ofrecer costos más bajos de fletes o menores tiempos de entrega o servicios logísticos y de valor agregado que las opciones de cruce existentes no ofrezcan actualmente. Más aún, esto sería insuficiente sin el desarrollo de un proyecto integral que concite el interés de actores locales y globales, de los ámbitos público y privado, vinculados con cadenas productivas, redes de transportación, consolidación, transformación y distribución de flujos.

Por lo pronto, en el contexto actual, el análisis de los datos recabados de rutas de origen y destino, tiempos de tránsito y costos de los fletes muestran, en general, una posición poco ventajosa para el eventual corredor multimodal del Istmo frente a las opciones de cruce existentes en Estados Unidos y Panamá.

Así, desde la perspectiva del espacio de redes y flujos de la globalización, se observa que el proyecto de desarrollo de un corredor interoceánico de transporte multimodal en el Istmo de Tehuantepec se produce en un ámbito de fuerte disputa internacional, en el cual los corredores establecidos -que concentran 


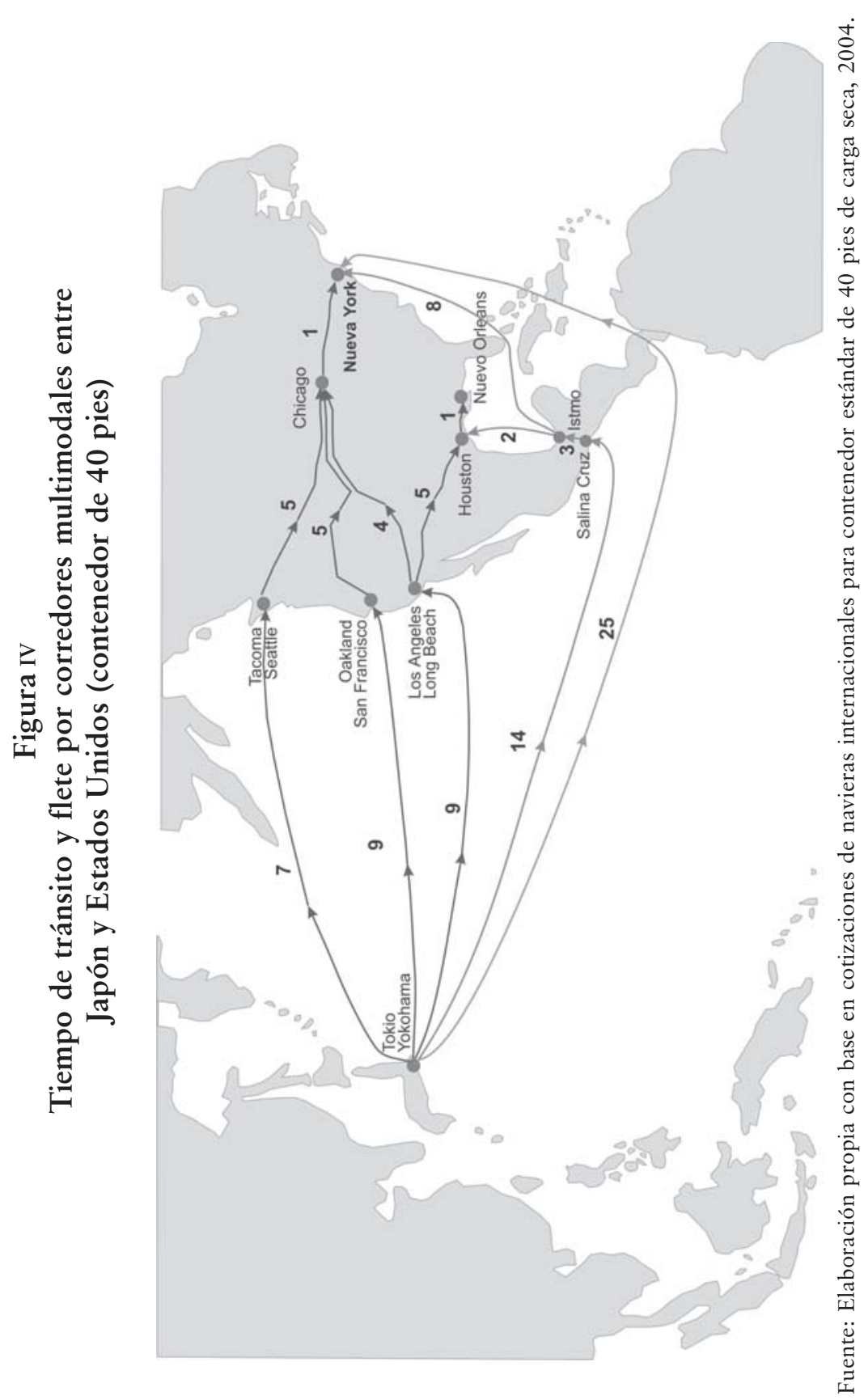




\begin{tabular}{lcccccc}
\hline \multicolumn{1}{c}{ Destino } & Canal & $\begin{array}{c}\text { Flete usD } \\
\text { Puente } \\
\text { Panamá }\end{array}$ & $\begin{array}{c}\text { Istmo } \\
\text { terrestre }\end{array}$ & $\begin{array}{c}\text { Canal } \\
\text { Panamá }\end{array}$ & $\begin{array}{c}\text { Tiempo (días) } \\
\text { terrestre }\end{array}$ & Istmo \\
\hline Nueva York & 3,430 & 4,130 & 5,150 & 25 & 14 & 25 \\
Chicago & - & 3,687 & 5,300 & - & 13 & 22 \\
Houston & - & 3,578 & 4,750 & - & 14 & 19 \\
Nueva Orleáns & - & 3,610 & 4,900 & - & 15 & 20 \\
\hline
\end{tabular}

Fuente: Elaboración propia con base en cotizaciones de navieras internacionales para contenedor estándar de 40 pies de carga seca, 2004.

intereses de actores sociales fuertes, como empresas navieras y de transporte multimodal con alta sofisticación tecnológica, empresas ferroviarias, puertos, transportistas, agentes de carga y operadores logísticos- buscan consolidar sus posiciones en el mercado. Principalmente los puentes terrestres estadounidenses y el Canal de Panamá muestran un fuerte grado de consolidación así como una gran inercia de navieras, distribuidores y operadores de transporte multimodal para utilizar estas vías ya comprobadas (Martner, 2000).

En este sentido, no se deben esperar grandes movimientos de carga interoceánica en el corto y mediano plazos, salvo que se produjese una reestructuración total de los flujos en el ámbito internacional, lo cual es poco probable por las economías de escala, la potencialidad, los intereses y las inversiones involucradas en los actuales corredores y puentes terrestres.

Por otra parte, el desarrollo del corredor como un simple cruce de mercancías entre los dos océanos no implicaría grandes beneficios para la región, salvo que fuese acompañado de actividades logísticas que agreguen valor a los flujos y generen actividad productiva en la zona. Seguramente el Istmo adquiriría un mayor valor estratégico en el concierto económico internacional si se desarrolla como un nodo regional de concentración, procesamiento y distribución de flujos de bienes intermedios e información, asociados a cadenas productivas globales, que si se instaura como un simple cruce internacional de carga. Pero aun en esta tesitura tendría que competir con los hubs regionales implantados en Panamá, Bahamas, Jamaica, Puerto Rico y Florida (Martner, 2000).

En definitiva, las modificaciones productivas y tecnológicas en la economía-mundo capitalista que sentaron las bases para la conformación de redes globales de transporte y para la aparición de nuevos corredores multimodales en zonas específicas del orbe, 
ubican al Istmo de Tehuantepec en un nuevo contexto internacional que, normalmente, se omite, desconoce o no se considera en el debate actual. Es evidente la pérdida de importancia geoeconómica y geopolítica del Istmo ante el desarrollo de corredores intermodales en otras zonas del continente. Por eso, es muy recomendable que la región del Istmo no se juegue su estrategia de desarrollo o crecimiento económico en una sola carta, es decir, en la de la conformación y operación del corredor interoceánico de transporte multimodal. La región del Istmo, con la complejidad política y socioeconómica expresada -entre otras cosas en elevados índices de pobreza y marginación, coexistencia de gran diversidad de etnias pauperizadas y un conflicto de larga duración sobre la tenencia de la tierra y los usos del suelo- tiene que formar parte de un proyecto de desarrollo regional más amplio en el sureste del país, donde no necesariamente el corredor interoceánico de transporte aparezca como el pivote sobre el que se estructuren las actividades (Martner, 2000).

\subsubsection{El corredor internacional del Sistema de Seguridad Multimodal Transpacífico articulado a los puertos de Lázaro Cárdenas y/o Manzanillo}

En la actualidad, el puerto mexicano que ha consolidado el mayor corredor multimodal, con servicios regulares de trenes de doble estiba de contenedores, es Manzanillo, ubicado en el centro del litoral del Pacífico. Dicho corredor se mueve desde el puerto hasta la ciudad de México, pasando por Guadalajara y diversas ciudades del Bajío. Su vertiginosa penetración se refleja en una participación creciente en el movimiento de los flujos de contenedores. Durante el año 2004, cerca de 40\% de los contenedores de Manzanillo, con origen o destino en el interior del país, se transportaron por ferrocarril. Así, este puerto está teniendo una ventaja competitiva adicional, misma que eventualmente le permitirá ir ascendiendo en la jerarquía de la red global.

No obstante, en años recientes otro puerto con potencial en el Pacífico mexicano busca insertarse en las redes globales de transportación mediante la captación de segmentos de los crecientes flujos de contenedores procedentes de China y del Lejano Oriente. Se trata del puerto de Lázaro Cárdenas, en Michoacán, lugar donde se reactivó la terminal especializada de contenedores mediante el ingreso de un operador global, como es el caso de la empresa Hutchinson Ports, que tiene ambiciosos planes de expansión, en 100 hectáreas de dicho recinto portuario, para crear la 
terminal de contenedores más grande del país. Por lo pronto, el reinicio de operaciones en la terminal de contendores existente permitió poner en funcionamiento el corredor multimodal de trenes de doble estiba desde y hacia la ciudad de México.

Dos hechos relevantes e interconectados entre sí se suman a este entorno. Por una parte, en la reunión de la Asia Pacific Economic Cooperation (APEC) 2002, realizada en México, se presentó el llamado Proyecto Bandera del país anfitrión, bajo el nombre de Sistema de Seguridad Multimodal Transpacífico (Trans Pacific Multimodal Security System), donde se planteó desarrollar un corredor multimodal internacional que cruzaría por los puertos de Manzanillo y/o Lázaro Cárdenas. Esta iniciativa pretende enlazar principalmente flujos de contenedores entre el sudeste asiático (concentrados en el hub de Singapur) y el centro de los Estados Unidos (con hub concentrador en Kansas City), atravesando por los citados puertos mexicanos y la frontera norte. Se trataría de una vía complementaria pero que, a la vez, competiría con los puentes terrestres estadounidenses, articulados desde los puertos de Long Beach y Los Ángeles.

Por otra parte, el Acuerdo de Concertación para el Desarrollo de los Corredores Multimodales, del año 2004, dio prioridad a los trabajos del subcomité de facilitación para la creación del corredor Lázaro Cárdenas-Pantaco-Nuevo Laredo, cuya finalidad es vincular los flujos entre Asia y el centro-este de Estados Unidos, utilizando la infraestructura y los servicios de transporte por el territorio nacional. También se avanzó en la conformación del subcomité del corredor Manzanillo-Nuevo Laredo que busca la integración de los flujos entre Asia y el este de Estados Unidos.

La implementación de los subcomités o grupos de trabajo resulta, por sí mismo, un ejercicio muy positivo que estimula el desarrollo de estrategias logísticas así como la colaboración entre los actores locales y globales vinculados al transporte multimodal y al comercio exterior.

No obstante, los proyectos tienen que solventar algunos aspectos que podrían cuestionar seriamente su viabilidad. En primer lugar, se requiere una coordinación exhaustiva entre autoridades portuarias, operadores de terminales, empresas ferroviarias, aduanas y la Procuraduría General de la República (PGR), entre otros, para que el corredor permita un flujo continuo de mercancías. Tal coordinación implica no sólo aspectos operativos, reflejados principalmente en los tiempos de traslado, sino un manejo de precios por parte de los distintos actores que 
sostenga la competitividad del corredor frente a otras vías ya existentes.

En segundo lugar, hay algunos puntos críticos en la infraestructura que podrían restar competitividad al corredor. El trazo de la vía férrea en la Sierra Madre Occidental presenta pendientes y curvaturas que obligan a sobrecostos operativos, como la utilización de equipo de tracción adicional, y limita la extensión de los trenes (no mayores de 75 carros). Una adecuación y modernización de este tipo implica elevadas inversiones de capital que sólo la garantía de enormes flujos de carga puede compensar. Otras adecuaciones más fáciles de solventar serían la ampliación de los patios ferroviarios de maniobras en Laredo y Nuevo Laredo, para corresponder con el aumento de la demanda propiciada por el corredor.

A pesar de estas objeciones, en el llamado Proyecto Bandera, reseñado en el documento titulado Trans Pacific Multimodal Security System (TPMSS, 2002), se describen los resultados de algunas pruebas realizadas que avalarían la viabilidad del corredor multimodal en cuestión. Sin embargo, estos resultados están a todas luces incompletos y distan mucho de ofrecer una base sólida para tomar decisiones de inversión y operación. Sólo incluyen datos de distancia y tiempo de tránsito por el territorio mexicano (Manzanillo-Nuevo Laredo y Lázaro Cárdenas-Nuevo Laredo) y dejan pendientes tanto el análisis de los tramos anteriores y posteriores de la red multimodal de carga como el estudio de costos para demostrar que la ruta total utilizando puertos mexicanos es más económica frente a otras opciones.

De hecho, el argumento más socorrido para resaltar la viabilidad de estos corredores a partir del Acuerdo de Concertación para el Desarrollo de los Corredores Multimodales (2004) es el factor distancia (Castillo, 2005). Mayor distancia desde Los Ángeles-Long Beach hasta las ciudades del centro-este de Estados Unidos respecto de la que hay desde los puertos del Pacífico mexicano -como Lázaro Cárdenas, Manzanillo y el Istmo de Tehuantepec- hacia tales urbes. ¿Qué mejor prueba de la potencialidad de los corredores multimodales por los puertos mexicanos?

No obstante, este cálculo revela nuevamente hasta qué punto en las ciencias sociales, la geografía y la ingeniería están interiorizados los paradigmas convencionales de análisis espacial que ubican la unidad de análisis en las sociedades y espacios nacionales, dejando en segundo plano la visión global y las determinaciones de las redes globales sobre los territorios. 


\section{Cuadro 3}

Distancias de corredores intermodales desde puertos del Pacífico hacia ciudades del centro este de Estados Unidos (kilómetros)

\begin{tabular}{lccccc}
\hline \multicolumn{1}{c}{ De / a } & $\begin{array}{c}\text { Los Ángeles/ } \\
\text { Long Beach }\end{array}$ & Ensenada & Manzanillo & $\begin{array}{c}\text { Lázaro } \\
\text { Cárdenas }\end{array}$ & $\begin{array}{c}\text { Istmo de } \\
\text { Tehuantepec }\end{array}$ \\
\hline San Antonio, Tx. & 2,317 & 2,111 & 1,913 & 1,808 & 1,920 \\
Houston, Tx. & 2,708 & 2,502 & 2,001 & 1,896 & 1,582 \\
Dallas, Tx. & 2,434 & 2,743 & 2,228 & 2,123 & 2,001 \\
Memphis, Ten. & 3,205 & 3,276 & 3,079 & 2,974 & 2,483 \\
Kansas City & 2,735 & 3,017 & 3,160 & 3,055 & 2,826 \\
St. Louis, Ms. & 3,282 & 3,532 & 3,441 & 3,336 & 2,885 \\
Chicago, Ills. & 3,474 & 3,776 & 3,843 & 3,738 & 3,275 \\
\hline
\end{tabular}

Fuente: Elaborado por el Instituto Mexicano del Transporte (IмT), con base en Red Ferroviaria Mexicana, ArcInfo, US Federal Maritime Comisión y Rail Waybill Data.

En efecto, al realizar un simple ejercicio geográfico que consiste en medir las distancias de los corredores multimodales, desde el origen al destino, es decir, si ponemos el foco del análisis en un ámbito espacial mayor, que permita observar la vinculación de bloques geoeconómicos específicos (la Cuenca del Pacífico, en este caso), la percepción del problema y las conclusiones se modifican totalmente. Bajo esta nueva mirada, resulta que la distancia desde países del noreste y sudeste asiático al centro-este de Estados Unidos es, en casi todos los casos, notablemente superior por los puertos mexicanos que a través del hub californiano (Los Ángeles/Long Beach). Para estos flujos de puerta a puerta la vía del Istmo de Tehuantepec es la que tiene las distancias más largas. El corredor vía Manzanillo o Lázaro Cárdenas aparece en una posición intermedia, en tanto que la ruta por Ensenada es la única que muestra distancias similares a la de Los Ángeles-Long Beach.

Desde luego la distancia es sólo un elemento dentro de un análisis de los corredores multimodales, pues como señala Castillo (2005: 23): "Más corto no es más rápido". No obstante, esta desventaja inicial de los corredores a través de los puertos mexicanos del Pacífico sólo podría compensarse con mayor eficiencia operativa, menores tiempos de tránsito por kilómetro y/ o con el desarrollo de actividades logísticas sobre el corredor para la transformación, agregación de valor y distribución de los flujos de determinadas cadenas productivas que, por lo mismo, se verían impelidas a utilizar los servicios de este eje.

Asimismo, la negociación entre regiones con actores institucionales, locales y globales parece imprescindible para impulsar un eje de este tipo. En el caso del corredor multimodal Asia- 


\section{Cuadro 4}

Comparación de distancias entre Singapur y ciudades del centro este de Estados Unidos por cinco corredores intermodales transpacíficos (kilómetros)

\begin{tabular}{lccccc}
\hline Singapur / a & $\begin{array}{c}\text { Vía } \\
\text { Los Ángeles/ } \\
\text { Long Beach }\end{array}$ & $\begin{array}{c}\text { Vía } \\
\text { Ensenada }\end{array}$ & $\begin{array}{c}\text { Vía } \\
\text { Manzanillo }\end{array}$ & $\begin{array}{c}\text { Vía } \\
\text { Lázaro } \\
\text { Cárdenas }\end{array}$ & $\begin{array}{c}\text { Vía } \\
\text { Istmo de } \\
\text { Tehuantepec }\end{array}$ \\
\hline San Antonio, Tx. & 16,520 & 16,533 & 18,190 & 18,330 & 19,258 \\
Houston, Tx. & 16,911 & 16,923 & 18,278 & 18,418 & 18,920 \\
Dallas, Tx. & 16,637 & 17,165 & 18,506 & 18,646 & 19,340 \\
Memphis, Ten. & 17,408 & 17,698 & 19,357 & 19,496 & 19,821 \\
Kansas City & 16,938 & 17,438 & 19,437 & 19,576 & 20,164 \\
St. Louis, Ms. & 17,485 & 17,953 & 19,718 & 19,858 & 20,224 \\
Chicago, Ills. & 17,677 & 18,198 & 20,121 & 20,260 & 20,613 \\
\hline
\end{tabular}

Fuente: Elaborado por el Instituto Mexicano del Transporte (IMT), con base en MaritimeChain.com, ArcInfo, US Federal Maritime Comisión y Rail Waybill Data.

Lázaro Cárdenas-Estados Unidos, el gobierno de Missouri, el SmartPort de Kansas City y la empresa ferroviaria Kansas City Southern (operadora de la ruta Lázaro Cárdenas-centro-este de Estados Unidos, entre otras) negocian con el gobierno del estado de Michoacán, con la administración portuaria y con actores locales y federales mexicanos para activar este corredor que le daría salida directa a la Cuenca del Pacífico a través de una empresa de su propia región, como es el caso de Kansas City Southern Lines, la cual no tiene acceso al Pacífico por los puertos estadounidenses. Otro actor global relevante aquí es la empresa china Hutchinson Ports (Hong Kong), principal operador mundial de terminales de contenedores que ha tenido acceso a los puertos estadounidenses.

En todo caso, esto no evitará la competencia con el corredor multimodal estadounidense, el cual tiene importantes economías de escala por los inmensos buques que arriban a sus costas, los enormes volúmenes de carga manejados en sus terminales portuarias y los largos trenes de doble estiba de contenedores que circulan por sus puentes terrestres.

Por otra parte, uno de los argumentos más frecuentes acerca de la viabilidad de los corredores multimodales del Pacífico mexicano, vía Lázaro Cárdenas, Manzanillo o el Istmo de Tehuantepec, es el de la saturación inevitable de los puertos californianos debida al fuerte crecimiento de los flujos de carga contenerizada, impulsado por China y otros países del noreste y sureste asiáticos (Castillo, 2005). Sin embargo, la inviabilidad de Los Ángeles-Long Beach para crecer después del 2009 (Castillo, 2005) no 
está comprobada pues las mejoras operativas y tecnológicas, así como la probable expansión de la infraestructura portuaria ganándole terreno al mar, permitiría ampliar el horizonte de saturación de tales puertos.

Por lo pronto, de acuerdo con un análisis preliminar, Ensenada sería el puerto del Pacífico mexicano mejor posicionado desde el punto de vista geográfico para complementar al corredor multimodal de los puertos californianos. En el siguiente apartado se hacen algunas precisiones sobre su potencialidad en el contexto de las redes globales de transportación.

\subsubsection{El corredor intermodal de Ensenada, Baja California}

En los años noventa, el eje Asia-centro este de Estados Unidos se consolidó como el principal corredor multimodal internacional (marítimo-terrestre) y, en especial el hub californiano, constituido por los puertos de Los Ángeles y Long Beach, adquirió una clara supremacía como el nodo articulador principal del mencionado corredor multimodal.

En este contexto, el puerto de Ensenada, ubicado en Baja California, México, a escasos $120 \mathrm{~km}$ de California, no puede escapar a una nueva disyuntiva que implica retos y oportunidades con repercusiones significativas para su futuro inmediato y de largo plazo. En efecto, en la coyuntura actual, el abanico de posibilidades de desarrollo del puerto abarca desde su permanencia en una posición marginal dentro de la red global de puertos y transporte multimodal hasta su reposicionamiento como hub intermedio en el concierto global. Este último escenario supone revalorar su localización geográfica bajo una concepción distinta de desarrollo portuario, en el cual la idea de $h u b$ o nodo articulador de corredores intermodales adquiere un papel central en el análisis.

El trabajo del Instituto Mexicano del Transporte, "Estudio de Competitividad del Corredor Multimodal Ensenada-Noreste de México-Estados Unidos" (2003), da un primer paso en este sentido al analizar el puerto de Ensenada en un contexto de la geografía del transporte que traspasa su ámbito local o regional inmediato. Para establecer su potencialidad, se buscó descifrar las claves de su inserción en la red global de transporte multimodal. La unidad de análisis se situó en el área de la Cuenca del Pacífico con el estudio de sus rutas y corredores, de sus puntos de origen-destino más importantes y de la evolución tecnológica, operativa y logística de los principales actores del transporte internacional. Con base 
en los datos obtenidos, es posible reflexionar sobre las potencialidades de este puerto mexicano para integrarse como nodo complementario dentro de una red intermodal de gran envergadura, cuyo principal nodo articulador en Norteamérica seguirá siendo el hub californiano de Los Ángeles-Long Beach.

A partir de un análisis comparativo de distancias y tiempos de diversas regiones del Lejano Oriente, tanto del noreste asiático (Tokio) como del centro-este asiático (Hong Kong) y del sudeste asiático (Singapur), se observa que el puerto de Ensenada aparece en una buena posición competitiva en distancia y tiempo frente a la opción de los puentes terrestres estadounidenses articulados a través del hub californiano de Los Ángeles-Long Beach para articularse con las ciudades del centro-este de Estados Unidos.

\section{Figura $\mathrm{V}$}

\section{Corredores Intermodales Transpacíficos} (Singaropre-Centro Este de los Estados Unidos de América)

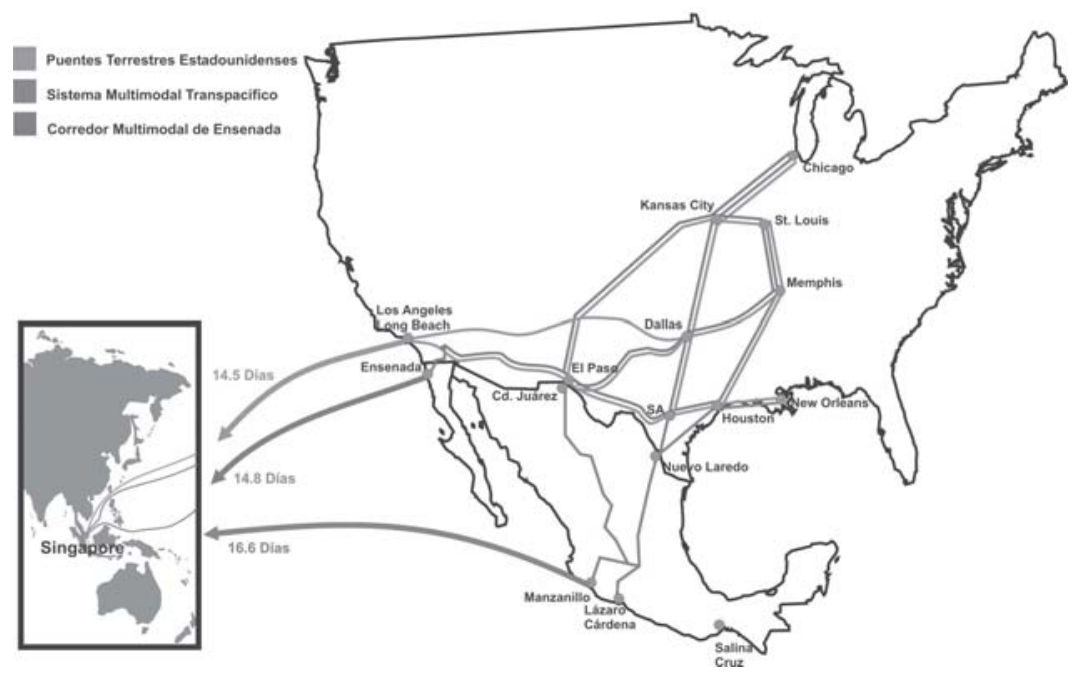

Fuente: Elaborado por el IMT con base en datos de BP Marine.

La excesiva concentración de flujos de contenedores procedentes de Asia en el hub de Los Ángeles-Long Beach, con signos de saturación en temporadas pico, sumada a la competitividad en distancias y tiempos de recorrido del puerto de Ensenada con respecto a los flujos destinados al centro-este de los Estados Unidos, son evidencias contundentes de esta ventana de oportuni- 
dad que se le abre al puerto bajacaliforniano. Ahora bien, la posibilidad de explotar este corredor pasa necesariamente por el desarrollo de la vía corta de ferrocarril Ensenada-Tecate y de su conexión con otra vía corta en California: la Ruta del Desierto, que requiere ser modernizada por el condado de San Diego.

El eventual desarrollo de este corredor intermodal implicaría un rápido ascenso del movimiento de contenedores que se pudiera absorber durante la primera fase con obras de ampliación de la actual terminal, cuya capacidad máxima, de acuerdo con la empresa que la opera, sería de 500 mil teus anuales. Sin embargo, en una visión de mediano y largo plazos, las características y el emplazamiento actual de la infraestructura portuaria resultan notoriamente insuficientes, lo que llevaría a estudiar y evaluar diversas posibilidades de crecimiento del puerto.

Punta Colonet, ubicada un centenar de kilómetros al sur de Ensenada, es señalada por el gobierno de Baja California como el lugar ideal para desarrollar un megapuerto de contenedores, que articularía territorialmente los corredores transpacíficos vinculados al noroeste de México y el centro-este de Estados Unidos. Desde luego, la evaluación de tal propuesta sobrepasa los límites de este trabajo, sin embargo, no puede dejarse de señalar el hecho de que se trata de un desarrollo en despoblado, donde no sólo se requiere construir un puerto con su terminales sino también carreteras, vías férreas y el desarrollo urbano de una nueva localidad. Hasta el momento no queda claro quién o quiénes cubrirían tan grandes inversiones.

\subsection{Canales secos y canales búmedos en Centroamérica}

\subsubsection{Los canales de Nicaragua}

Nicaragua es el país centroamericano que mayor empeño ha puesto en explorar la posibilidad de desarrollar un corredor intermodal bioceánico que cruce, por ferrocarril y/o carretera, del océano Pacífico al Atlántico (denominado canal seco en todo el istmo centroamericano) y también ha desarrollado el proyecto para construir un canal húmedo, llamado Gran Canal, que tendría las características de una vía acuática interoceánica del tipo del Canal de Panamá, pero con mayores dimensiones y profundidad.

De hecho, en 2003 se discutían tres proyectos en Nicaragua. Dos de ellos similares, corresponden a la construcción de canales secos o corredores intermodales apoyados por una línea férrea que una al Caribe con el Pacífico, por donde cruzarían tre- 
nes para transportar contenedores que desembarquen o embarquen en puertos nicaragüenses ubicados en ambos mares. Uno de los proyectos, que impulsa el consorcio Canal Interoceánico de Nicaragua (CINN), propone construir dos puertos: el primero, en Monkey Point, sobre el litoral del Atlántico y el segundo en Brito, en el Pacífico sur del país. El diseño del proyecto del CINN incluye la construcción de una carretera paralela a la línea del ferrocarril. El costo de la primera fase de este proyecto está calculado en 2,600 millones de dólares (Confidencial, 2003).

Por otro lado, el consorcio sIT/Global, que cuenta con inversionistas de Canadá, Estados Unidos, Europa, Taiwán y otros países asiáticos, plantea solamente construir un puerto en el Caribe, en Monkey Point, y usar las instalaciones de Puerto Corinto, en el Pacífico, para la entrada y salida de los contenedores que serían transportados por ferrocarril. El proyecto de SIT/ Global, a un costo inicial de 1,600 millones de dólares, se encuentra en la fase de estudios de impacto ambiental, a cargo de una empresa canadiense, que deberán ser aprobados por el gobierno de Nicaragua para otorgar la autorización final de construcción de la obra, cuyos intentos datan de hace una década (Confidencial, 2003).

Por último, el proyecto del "canal húmedo consiste en usar los ríos Escondido, Rama y Oyate, en el Caribe y centro del país; y el lago de Nicaragua o Cocibolca, y además en abrir un canal en el istmo de Rivas, por donde pasarían los barcos portacontenedores. La idea de los inversionistas de la Fundación Gran Canal es dragar los caudales de esos ríos y las partes costeras del lago Cocibolca y abrir el canal entre La Virgen y Brito, en el sur del país, para facilitar la movilización de barcos de gran calado. Una vez que se realicen los estudios de factibilidad financiera y ambiental y que el gobierno apruebe el proyecto, la construcción de ese canal húmedo duraría entre ocho y diez años. Se crearían dos grandes puertos, en el Caribe y el Pacífico, y dos pequeñas instalaciones portuarias en el lago Cocibolca. Esta obra necesitaría una inversión de entre 20 y 25 mil millones de dólares, de acuerdo con los proyectistas nicaragüenses (Confidencial, 2003).

De acuerdo con el vicepresidente de la Fundación Gran Canal, Adolfo Evertz, la idea es que no sea solamente un país el que aporte los fondos, sino una sociedad financiera plural para evitar situaciones como las que vivió Panamá, en la administración del canal. "El gobierno primero tiene que convocar a la comunidad internacional para interesarla en participar en la formación de la 
empresa que se encargaría de los estudios a fondo y luego en la construcción del canal" (Tiempos del Mundo, 2003: 4).

Las tres propuestas se encuentran en fase de anteproyecto o estudios de prefactibilidad ambiental, sin embargo, se observa una ausencia de análisis de la geografía de redes y flujos, del origen-destino de las mercancías y del tamaño de la demanda potencial por los corredores y canales. Asimismo, en el caso del proyecto del Gran Canal, el argumento más contundente se refiere a la estrechez de las esclusas del Canal de Panamá, que no permiten el tránsito de grandes buques, llamados Postpanamax, que navegan en número creciente por mares y océanos. Sin embargo, hace poco la Autoridad del Canal de Panamá inició estudios que derivarán eventualmente en la construcción de un juego de esclusas adicional para estos grandes navíos.

\subsubsection{Opciones de corredores intermodales bioceánicos (canales secos) en Centroamérica}

En 2001, el "Estudio Centroamericano de Transporte" (ECAT 2001), realizado por la Secretaría de Integración Económica Centroamericana (SIECA), analizó las opciones de desarrollo de canales secos en la región, a partir de los proyectos hechos e impulsados por los gobiernos y los grupos privados. Este documento plantea que "al cumplirse cerca de un siglo de la construcción del Canal de Panamá, han surgido, debido a las limitaciones del mismo ante el crecimiento de las dimensiones de los buques y una demanda de tráfico cada vez mayor, proyectos de opciones de comunicación entre los océanos Atlántico y Pacífico en la región del Centro de América, dada su posición y configuración geográfica, que van desde corredores interoceánicos viales o ferroviarios a canales húmedos" (ЕСAT, 2001: 41).

La configuración geográfica de la subregión -un istmo con litorales en ambos océanos, con longitudes prácticamente iguales y distancias entre los puertos del Pacífico y el Atlántico, que oscilan entre 285 kilómetros para la dupla Complejo Portuario Limón Moín-Caldera, en Costa Rica, hasta 749 kilómetros para el canal vial Corinto, Nicaragua, a Complejo Portuario LimónMoín en Costa Rica- genera la posibilidad de activar los canales secos para el transporte entre los puertos de carga como opción para los propios países de comerciar con todas las regiones del mundo o para utilizar los puertos centroamericanos como plataformas de transbordo de carga (ECAT, 2001). 
Aunque se advierte que "ya se trate de enlaces por carreteras o vías férreas los canales secos se consideran para grandes volúmenes de carga. No es conveniente tenerlos como opciones para el intercambio comercial del Mercado Común Centroamericano, ya que éste representa una muy pequeña cantidad de carga, que está siendo servida por el transporte automotor. Adicionalmente, se debe considerar el hecho de que ninguna de las opciones presentadas, ya sea carretera o ferroviaria, compite con la longitud de la vía terrestre de Panamá. En efecto, la distancia del canal seco panameño, constituido por una red ferroviaria para trenes de doble estiba que se encuentra en operaciones desde 2002, es de sólo 80 kilómetros. No obstante, el ECAT plantea que a través de los años se han identificado diversos corredores viales interoceánicos, los cuales fueron, de alguna manera, evaluados pero nunca llegaron a convertirse en proyectos concretos.

\begin{tabular}{|c|c|c|c|c|}
\hline \multicolumn{5}{|c|}{$\begin{array}{c}\text { Cuadro } 5 \\
\text { Centroamérica, posibles corredores multimodales } \\
\text { carretero-marítimos } \\
\text { (longitud en kilómetros y tiempo estimado de viaje en horas) }\end{array}$} \\
\hline Núm. & Litoral Pacífico & Litoral Atlántico & $\begin{array}{c}\text { Longitud } \\
\text { en kilómetros }\end{array}$ & $\begin{array}{l}\text { Tiempo estim. } \\
\text { de viaje (horas) }\end{array}$ \\
\hline 1 & Caldera & Limón-Moín & 285 & 9 \\
\hline 2 & Acajutla & Santo Tomás/Barrios & 354 & 14 \\
\hline 3 & Quetzal & Santo Tomás/Barrios & 412 & 12 \\
\hline 4 & San Lorenzo & Cortés & 427 & 12 \\
\hline 5 & Cutuco & Cortés & 464 & 16 \\
\hline 6 & Acajutla & Cortés & 527 & 17 \\
\hline 7 & Corinto & Cortés & 589 & 19 \\
\hline 8 & Corinto & Limón-Moín & 749 & 28 \\
\hline
\end{tabular}

Fuente: Perfil del proyecto del Corredor Interoceánico de Transporte Puerto CortésPuerto Corinto, Secretaría de Integración Económica Centroamericana, SIECA, noviembre de 1997.

1 Tiempo de marcha, tiempo en cruce fronteras (tres horas promedio), tiempo puestos de control y comidas.

Asimismo, "se evaluó el enlace de pares de puertos marítimos centroamericanos, situados uno en cada litoral, por un ferrocarril, considerándose que este medio de transporte, por tener una mayor capacidad de acarreo que el automotor por carretera, puede ser una alternativa más viable para la movilización de decenas de millones de toneladas, que se espera será el tráfico, tanto doméstico como de transbordo internacional (ECAT, 2001: 42).

En el caso de los canales interoceánicos servidos por ferrovías, se identificaron algunos costos de inversión en infraestruc- 


\section{Cuadro 6 \\ Centroamérica, posibles corredores multimodales ferroviario-marítimos}

\begin{tabular}{|c|c|c|c|c|}
\hline Países & $\begin{array}{c}\text { Puertos } \\
\text { Litoral Pacífico }\end{array}$ & $\begin{array}{c}\text { Puertos } \\
\text { Litoral Atlántico }\end{array}$ & $\begin{array}{l}\text { Longitud } \\
(\mathrm{km})\end{array}$ & $\begin{array}{c}\text { Costo } \\
\text { (millones USD) }\end{array}$ \\
\hline Guatemala & Puerto Quetzal & $\begin{array}{l}\text { Santo Tomás/ } \\
\text { Barrios }\end{array}$ & 430 & 1,800 \\
\hline $\begin{array}{l}\text { El Salvador/ } \\
\text { Honduras }\end{array}$ & Cutuco & Puerto Cortés & 410 & 2,200 \\
\hline $\begin{array}{l}\text { Nicaragua } \\
\text { Nicaragua/ }\end{array}$ & Pie de Gigante & Monkey Point & 390 & 2,700 \\
\hline Costa Rica & No determinado & Puerto Limón & 360 & 1,700 \\
\hline
\end{tabular}

Fuente: Análisis prospectivo de las alternativas de canales secos. Estudio Centroamericano de Transporte, Secretaría de Integración Económica Centroamericana, Parte 3, Capítulo 7, вСЕОМ, diciembre de 2000.

tura que consideran la vía, mejora y ampliación de los puertos marítimos terminales. En el cuadro 6 se muestran las opciones de canales interoceánicos ferroviarios que se pueden considerar en Centroamérica, indicando la longitud, terminales portuarias en cada litoral y el costo de construcción de cada uno de ellos (ECAT, 2001: 42).

Esta proliferación de proyectos plantea una imagen del Istmo centroamericano lleno de cruces intermodales o bioceánicos que vinculan los flujos entre la Cuenca del Pacífico y la del Atlántico. Sin embargo, la idea de segmentación de un territorio tan escaso en múltiples redes internacionales de transporte es poco realista, pues una característica fundamental del espacio de redes de la globalización es la concentración de flujos en pocos puntos o hub selectos, con una mayor intensidad y diversidad de servicios, que generan mayor rentabilidad por economías de escala y de alcance. En el fondo, el ECAT no logra despegarse de esas visiones fragmentadas dentro de las ciencias sociales que ubican la unidad de análisis en el espacio-nación, sin observar las determinaciones globales en que se desenvuelven las redes multimodales de transportación.

En todo caso, la Secretaría de Integración Económica Centroamericana (SIECA) debiera evaluar la viabilidad de estos proyectos como opciones para la plataforma logística instalada en el Canal de Panamá. Para ello es conveniente analizar la demanda de dicha plataforma así como su capacidad y posibilidades de ampliación. Por otra parte, se debe profundizar en los costos de inversión y operación de las diferentes opciones de canales interoceánicos así como en las estimaciones de ingresos esperados 


\section{Figura VI}

Proyectos de corredores intermodales internacionales en México y Centroamérica, 2003

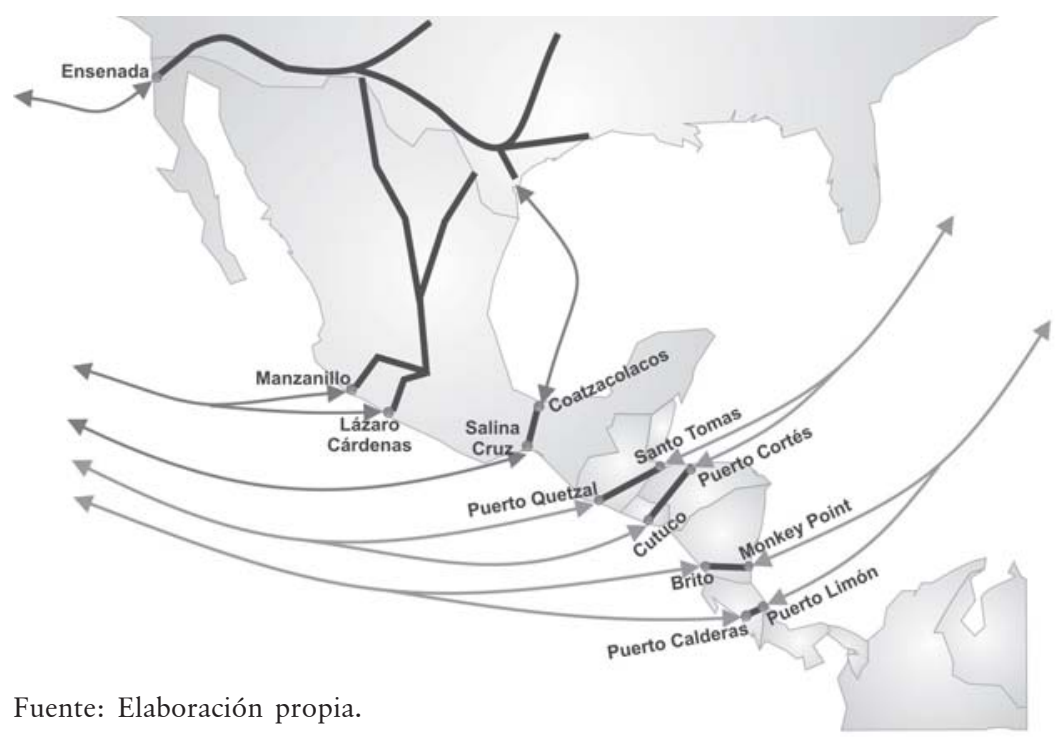

por la operación de los canales para establecer la factibilidad financiera de cada opción.

\section{Conclusiones preliminares}

Aunque todavía queda un largo camino por recorrer en el estudio de un tema que parece recurrente en los últimos años, el avance en la caracterización de los corredores multimodales a la luz del enfoque socioterritorial del espacio de redes y flujos de la globalización, así como su diferenciación respecto de la dicotomía entre los corredores de transporte tradicionales y los corredores comerciales, representa por sí mismo un aporte de investigación necesario tanto para los estudios de esta área del conocimiento como para la elaboración de planes maestros de transporte ${ }^{11} \mathrm{y}$, en general, para la formulación de políticas públicas de infraestructura y tecnología.

De hecho, el enfoque socioterritorial propuesto aporta un marco de análisis que permite comprender de manera global la

${ }^{11}$ En mayo de 2006 salió la convocatoria internacional para el Desarrollo del Plan Maestro de Corredores Multimodales en México, lanzada por la Secretaría de Comunicaciones y Transportes (SCT) con el apoyo de la Agencia de Comercio y Desarrollo de los Estados Unidos. 
lógica estructural y la dinámica de los corredores multimodales, cuya configuración y reconfiguración constante es propiciada por los trabajos de actores sociales concretos que operan con una racionalidad situada (Coq, 2003) en espacios diferenciados dentro del sistema-mundo. Metodológicamente, el traslado de la unidad de análisis hacia la conformación de un espacio global (al estilo del sistema-mundo capitalista de Wallerstein) es el elemento que permite poner a la luz tales estructuras, configuraciones, dinámicas y tendencias que pasan inadvertidas para los países de la región, al punto de que se han multiplicado, en cada uno de ellos, los proyectos para construir grandes obras de infraestructura de transporte (corredores internacionales, megapuertos, megaterminales, etc.) basados simplemente en los datos de la apertura comercial en curso y en supuestas trayectorias de los flujos que no se dan o no se sustentan más que en la creación de nueva infraestructura, sin analizar esa estructura más profunda que es la configuración de una red y un espacio global de flujos, cuya lógica de funcionamiento no es la misma que la de los Estados nacionales.

Por lo pronto, la incorporación en este trabajo de la categoría de hinterland de la globalización (o zona de influencia espacial globalizada) se revela como un aporte conceptual necesario para medir el alcance real de los corredores multimodales y, por tanto, delimitar el reparto de ámbitos territoriales concretos entre estos ejes, en un contexto donde la proliferación de proyectos de corredores no encuentra una justificación sólida a la luz de los enfoques, de corte neoclásico, económicos y geográficos. Al utilizar tal categoría, se concluye que no habrá un reconfiguración territorial a gran escala en el subcontinente (Norte y Centroamérica). En todo caso, ésta será paulatina puesto que las nuevas opciones viables son escasas y existe una fuerte inercia de los actores globales para utilizar los corredores multimodales establecidos (vía puentes terrestres y Canal de Panamá), cuyos niveles de consolidación son elevados.

En este punto de análisis preliminar, salvo en el caso de los corredores multimodales de Ensenada y Lázaro Cárdenas, donde se aprecian algunos datos que reflejan ciertas fortalezas, las demás propuestas no son claras en cuanto a ventajas geográficas y competencias sustantivas o la presencia de actores globales de la logística y la transportación de mercancías que faciliten la atracción de flujos masivos desde los derroteros existentes hacia los nuevos corredores. 
Lógicamente, el análisis de corredores multimodales a través de diversos puertos o puntos litorales de México y Centroamérica no se agota en esta instancia, sin embargo, el enfoque aquí propuesto ofrece una plataforma teórico-metodológica para el desarrollo de estudios más detallados que incluyan pormenores de los atributos físicos, operativos y organizacionales de dichos corredores, así como el análisis de las estrategias de los actores locales y globales relacionados con la transportación multimodal y con las actividades logísticas de cadenas de producción-distribución específicas.

\section{Bibliografía}

Banco Mundial (2003), Informe sobre el desarrollo mundial, World Bank, Nueva York.

Boske, Leigh y J. C. Cuttino (2003), "Measuring the economics and transportation impacts of maritime-related trade", Maritime Economics and Logistics, Palgrave Mcmillan, 5(2), Londres, pp. 133-157.

Braudel, Fernand (1953), El Mediterráneo y el mundo mediterráneo en la época de Felipe II, Fondo de Cultura Económica, Sección de Obras de Historia.

Braudel, Fernand (1985), El Mediterráneo. El espacio y la historia, México, Fondo de Cultura Económica, Colección Popular 431.

Braudel, Fernand (1986), La dinámica del capitalismo, México, Fondo de Cultura Económica, Colección Brevarios.

Caravaca, Inmaculada (1998), "Los nuevos espacios ganadores y emergentes”, Revista EURE, 24(73), Santiago de Chile, pp. 5-30.

Caravaca, Inmaculada et al. (2005), "Innovación, redes, recursos patrimoniales y desarrollo territorial". Revista EURE, 31(94), Santiago de Chile, pp. 5-24.

Castells, Manuel (1996), The rise of the network society. The information age: Economy, society and culture, vol. I, Oxford, Gran Bretaña, Blackwell Publishers Ltd. 
Castells, Manuel (1997), La era de la información. Economía, sociedad y cultura. La Sociedad Red, vol. I, Madrid, Alianza.

Castillo, Miguel Ángel (2005), “Tránsitos internacionales. Explosión inminente", Revista Transporte Siglo XXI, 75, México, pp. 23-25.

Confidencial (2003), "El Gran Canal: más grande que el de Panamá”, Confidencial, Semanario de Información y Análisis Político, año 8, 352, 17-23 de agosto, Nicaragua, pp. $15-18$.

Coq, Daniel (2003), "Epistemología, economía y espacio/territorio: del individualismo al holismo", Revista de Estudios Regionales, 69, Universidad de Sevilla, pp. 115-136.

Coq, Daniel (2005), "La economía vista desde el ángulo epistemológico, Revista Electrónica de Epistemología de las Ciencias Sociales, Universidad de Chile, pp. 1-5.

Cueva-Perus, Marco (1997), Sistema productivo, territorio y nación en América Latina: El caso de Panamá”, México, Instituto de Investigaciones Sociales, Universidad Nacional Autónoma de México.

ECAT (2001), Estudio Centroamericano de Transporte, Secretaría de Integración Económica Centroamericana (SIECA), Guatemala.

Froebel, F., J. Heinrichs y O. Kreye (1980), The new international division of labor, Cambridge, Cambridge University Press.

Fujita, Masahisa, P. Krugman y A. Venables (2000), Economía espacial. Las ciudades, las regiones y el comercio internacional, Barcelona, Ariel.

Herrera, Alonso, Agustín Bustos y Carlos Martner (2005), Diagnóstico del transporte de carga aérea en México, Publicación Técnica núm. 273, Instituto Mexicano del Transporte, sст, Querétaro, México.

Hiernaux, Daniel (1993), “Globalización, integración y nuevas dimensiones territoriales: una aproximación conceptual”, 
ponencia presentada en el seminario internacional Integración y Democratización en América Latina: el camino recorrido, julio, mimeografiado.

Hiernaux, Daniel (1999), Los senderos del cambio. Tecnología, sociedad y territorio, México, Plaza y Valdés Editores-Centro de Investigaciones Científicas (CIC).

Hogdson, G. M. (1998), "The approach of institutional Economics", Journal of Economics Literature, Xxxvi, March. Londres.

Instituto Mexicano del Transporte (2002), "El Corredor Internacional de Transporte del Istmo de Tehuantepec: límites y posibilidad", documento interno, inédito, Sanfandila, Querétaro, México.

Instituto Mexicano del Transporte (2003), "Estudio de competitividad del Corredor Multimodal Ensenada-Noreste de México-Estados Unidos”, documento interno, inédito, Sanfandila, Querétaro, México.

Krugman, Paul (1991), Geografía y comercio, Barcelona, Antoni Bosch.

Krugman, Paul (1997), La organización espontánea de la economía, Barcelona, Antoni Bosch.

Martner, Carlos (1999), "El puerto y la vinculación entre lo local y lo global”, Revista EURE, 25 (75), Santiago de Chile, pp. 103-120.

Martner, Carlos (2000), "Retos del Corredor Transístmico en el marco de las redes globales de transporte", Revista Mexicana de Sociología, 3, Instituto de Investigaciones Sociales, Universidad Nacional Autónoma de México, México, pp. 3-28.

Martner, Carlos (2001), "Modelos de desarrollo y articulación territorial del Puerto de Manzanillo", Argumentos, 39, Universidad Autónoma Metropolitana, División de Ciencias Sociales y Humanidades, Unidad Xochimilco, México, pp. 45-70. 
Martner, Carlos (2002), "Puertos pivotes en México: límites y posibilidades", Revista de la CEPAL, 76, Comisión Económica para América Latina y el Caribe, Naciones Unidas, Santiago de Chile, pp. 123-141.

Méndez, Ricardo (1997), Geografía económica: la lógica espacial del capitalismo global, Barcelona, Ariel.

Méndez, Ricardo (2002), "Innovación y desarrollo territorial: algunos debates teóricos recientes", Revista EURE, 28(84), Santiago de Chile, pp. 63-83.

Mongelluzzo, Hill (2003), "East vs. West”, The Journal of Commerce, 4 (11), Los Ángeles, pp. 7-12.

Piers (2002), “Ten Years Horizons”, Statistic Report, Verano VII, (II), Piers/Journal of Commerce, Los Ángeles.

Sánchez, Ricardo, J. Hoffmann, A. Micco, G. V. Pizzolitto, M. Stug y G. Wilmsmeir (2003), "Port efficiency and International Trade: Port efficiency as a determinant of maritime transport costs", Maritime Economics and Logistics, 5(2), Palgrave Mcmillan, Londres, pp. 199-218.

Santos, Milton (2000), La naturaleza del espacio, Barcelona, Ariel.

Sassen, Saskia (2003), "Localizando ciudades en circuitos globales”, Revista EURE, XXIX(88), Santiago de Chile, pp. 5-27.

Storper, M. y B. Harrison (1994), "Flexibilidad, jerarquía y desarrollo regional: los cambios de estructura de los sistemas productivos industriales y sus nuevas formas de articulación del poder en los años 90”, en Georges Benko y Alain Lipietz (comps.), Las regiones que ganan. Distritos y redes: los nuevos paradigmas de la geografía económica, Valencia, Edicions Alfons El Magnánim-Generalitat Valenciana-Diputació Provincial de Valéncia.

Tiempos del Mundo (2003), "Canal interoceánico, ¿un sueño posible?”, Semanario Tiempos del Mundo, núm. 48, 1218 de junio, Managua, pp. 3-6. 
TPMSS (2002), Trans Pacific Multimodal Security System, México, APEC-AMTI-Concamin y SCT.

Yocelevzky, Ricardo (1999), "La relevancia de las contribuciones de Immanuel Wallerstein para las ciencias sociales latinoamericanas", en Laura Baca e Isidro Cisneros (comps.), Los intelectuales y los dilemas políticos en el siglo XX, tomo I, México, Universidad Autónoma Metropolitana, Xochimilco.

Wallerstein, Immanuel (1992), "Las lecciones de los ochenta”, Argumentos, 15, Universidad Autónoma Metropolitana, Xochimilco, México, pp. 157-168.

Wallerstein, Immanuel (1996), Después del liberalismo, México, Siglo XXI.

Veltz, Pierre (1999), Mundialización, ciudades y territorios, Barcelona, Ariel.

Recibido: 3 de febrero de 2006. Reenviado: 18 de agosto de 2006. Aceptado: 17 de septiembre de 2006.

Carlos Daniel Martner Peyrelongue. Doctor en ciencias sociales, Área de Concentración en Sociedad y Territorio, UAM-Xochimilco, Jefe de la Unidad de Logística y Transporte Multimodal del Instituto Mexicano del Transporte (IMT), profesor de la materia de Globalización y Transporte en la Maestría de Sistemas de Transporte y Distribución de Carga de la Universidad Autónoma de Querétaro (UAQ), Investigador Nacional I del Sistema Nacional de Investigadores (SNI). 